\title{
Overview of Trending Medical Technologies
}

By Jean Marie Vianney Nkurunziza, Jean Claude Udahemuka, Jean Baptiste Dusenge, Francine Umutesi

Medical Technology Division, Rwanda Biomedical Center, Kigali, Rwanda

\section{ABSTRACT}

Healthy population is regarded as the most valuable asset of any country. Unfortunately, the health challenges that hinder mankind's wellbeing are enormously increasing. Examples include but are not limited to: the diversity of emerging diseases afflicting the global population, the projected demographic growth of elderly people who need consistent monitoring, the deficiency in medical staff, the lower density of physicians, and the challenging geographical location of the population from healthcare providers. The mitigation of such health challenges calls for novel technologies to improve patient outcomes. In this article, seven emerging technologies, namely: Wearable Devices and Internet of Things, Artificial Intelligence, Blockchain Technology or Distributed Ledger Technology, Robotics Technology, Telehealth and Telemedicine, Big Data Technology and Nanomedicine have been highlighted. For each discussed technology, its historical background, development drivers, market status and trends, significance to healthcare, key player companies, and associated challenges have been presented. The information contained in this paper was collected from different journal articles, websites, reports, conference proceedings, and books. It was observed that though the technologies discussed in this article show growth at different rates, healthcare technology development and implementation are very promising in revolutionizing the health sector and improving the health of the population. Therefore, healthcare providers and countries are recommended to put in place Healthcare Technology Assessment Programs to help them collect data regarding the technology efficacy, relevance, safety, outcomes, and alternative technologies towards better planning for healthcare services improvement.

Keywords - Wearable devices, Internet of Things, Blockchain, Telehealth and Telemedicine, Artificial Intelligence, Big Data, Nanomedicine, Market, Drivers, Challenges and Companies.

Copyright ( C 2021. This is an open-access article distributed under the terms of the Creative Commons Attribution License (CC BY): Creative Commons - Attribution 4.0 International - CC BY 4.0. The use, distribution or reproduction in other forums is permitted, provided the original author(s) and the copyright owner(s) are credited and that the original publication in this journal is cited, in accordance with accepted academic practice. No use, distribution or reproduction is permitted which does not comply with these terms.

\section{INTRODUCTION}

The triumph of modern medicine is axed to the emerging technological innovations, and there is no doubt that the medical expenditures and life expectancy are variables driven by technological progress. ${ }^{1-2}$ Medical technology uses scientific knowledge to improve healthcare by new and improved equipment to make work easier, pleasant, quick, and productive. ${ }^{3}$ The management and treatment of diseases have become largely dependent on innovation and discoveries in newer drugs, surgical techniques, diagnostic and therapeutic equipment. ${ }^{3}$ Medical doctors themselves are becoming more reliant on technology to diagnose and carry out treatments. ${ }^{4}$ The scope of medical technology is vast; it covers consumables (bandage, syringes, hearing aids, wheelchairs, etc.), implants (hips 
and knees, stents, pacemakers, etc.), medical equipment (imaging machinery, dialysis equipment, etc.), and in-vitro diagnosis. ${ }^{5}$ Technological innovations are appreciated by the general population because they enable a 4P-model for medicine (predictive, preventive, personalized, and participatory). ${ }^{6}$

The factors that reinforce the market for medical technology include advances in science and engineering, patent protection, increasing prevalence of chronic diseases, aging population, emerging pathogens, financial incentives of technology companies, mass media reports, public demand driven by direct-to-consumer advertising, consumer awareness and advocacy, rising prices of physician and hospital services, off-label use of drugs and devices, malpractice avoidance, strong and growing economies. $^{7-8}$ The maintainability of high quality of life in the aging population is probably the most significant underlying global which requires requiring technological mindset. ${ }^{9}$ For example, Japan has the longest life expectancy, and its aging population ratio is still increasing.

This has called for rising expenditures, giving concerns about the future inflation of health costs. ${ }^{10}$ In 2050 , $16 \%$ ( 1.5 billion) of the world's population will be above 65 years old. ${ }^{11}$ In China, 2.4 young people will have to support 7.9 old people in $2050 .{ }^{11}$ The physical nature, purpose, and stage of diffusion constitute the three ways to describe a healthcare technology. ${ }^{7}$ According to the stage of diffusion, medical technologies classification is presented in Table 1.

TABLE 1. Classification of Medical Technologies According to the Stage of Diffusion ${ }^{7}$

\begin{tabular}{|c|c|}
\hline $\begin{array}{c}\text { Medical } \\
\text { Technology Class }\end{array}$ & Explanation \\
\hline Future & $\begin{array}{c}\text { in a conceptual stage, anticipated, or in the } \\
\text { earliest stages of development }\end{array}$ \\
\hline Experimental & $\begin{array}{c}\text { undergoing bench or laboratory testing using } \\
\text { animals or other models }\end{array}$ \\
\hline Investigational & $\begin{array}{c}\text { undergoing initial clinical (i.e., in humans) } \\
\text { evaluation for a particular condition or indication }\end{array}$ \\
\hline Established & $\begin{array}{c}\text { considered by clinicians to be a standard } \\
\text { approach to a particular condition or indication } \\
\text { and diffused into general use }\end{array}$ \\
\hline $\begin{array}{c}\text { Obsolete/ } \\
\text { outmoded/ } \\
\text { abandoned }\end{array}$ & $\begin{array}{c}\text { Superseded by other technologies or } \\
\text { demonstrated to be ineffective or harmful }\end{array}$ \\
\hline
\end{tabular}

Today the actual figures for medical technologies are not available, but it is estimated that 500,000 different types of medical devices are in service. ${ }^{12}$ From 1960 to 2007, health care expenditure in OECD countries increased, on average, from $3.8-9.0 \%$ of GDP. ${ }^{1}$

In 2020 it was forecast that the global market for medical technology would achieve a volume of 490 billion euros ${ }^{11}$ In 2025, global turnover for medical devices is estimated at approx. 615 billion dollars. ${ }^{11}$

The main categories of healthcare technology include but are not limited to: drugs, biologics, devices/equipment and supplies, medical and surgical procedures, public health program, support systems, organization, and managerial systems. However, not all technologies fall neatly into the category, and certain hybrid technologies combine drugs and devices. ${ }^{7}$

In the past decade, the medical technology revenues have increased by $44.7 \%$ (USD $352 .{ }^{9}$ billion to USD $510 .{ }^{9}$ billion for 2011 and 2021, respectively), and the forecast is to reach USD 594.5 billion in $2024 .^{13}$ In 2022 , the strongest medical technologies segments will be in cardiology, imaging diagnostics, orthopedics, and surgery. These technologies will account for $50 \%$ of the market. ${ }^{11}$ Although there are giant companies in medical technology, 95\% of all medical technologies businesses are small and medium-sized companies (SME), with the majority having fewer than 50 employees. ${ }^{11}$ As of 2020, Medtronic Inc. was the leading medical technology company with a revenue of $30 .^{12}$ billion USD.

It was seconded by Johnson\&Johnson with total revenue of 23 billion USD. In a survey conducted about medical technology in Belgium, ${ }^{5} 106$ companies participated, and the results are that $67.9 \%$ were active in medical devices-consumables, $15.1 \%$ in In-vitro diagnosis, $12.7 \%$ in pharmaceutical products, $6.6 \%$ in para-pharmaceutical products, $43.4 \%$ in medical software, $40.6 \%$ in implants and $45.3 \%$ in medical equipment and systems. Medical technologies are classified into preventive, screening, diagnosis, rehabilitation, palliation, and treatment types. ${ }^{7}$

The technological acceptance and use expansion vary from society cultures. The Technology Acceptance Model developed by Davis, Theory of Planned Behavior, and Unified Theory of Acceptance and Use of Technology 2 (UTAUT2) developed by Venkatesh showed that perceived 
usefulness, perceived ease of use, price value, and habit are the key factors that determine the application and market expansion of a particular technology in a certain region. ${ }^{14,15}$ In addition to those factors, commercial-grade, durability, reliability, sustainability, technical support, disinfection, alarm management, network, and device security also advocate adopting a particular technology. ${ }^{16,17}$

\section{LITERATURE REVIEW}

It is not easy to cover all details of the medical technologies available in a single paper due to their diversity. In this paper, the following trending technologies are looked at: Health Wearables and Internet of Things, Artificial Intelligence (AI), Blockchain Technology (BCT) or Distributed Ledger Technology (DLT), Robotics Technology, Nanomedical Technology, Telemedicine and Telehealth, Big Data

\section{Health Wearables and Internet of Things}

Environmental, psychological, behavioral, and physiological domains that adversely impact the quality of life are recognized by the World Health Organization. ${ }^{19}$ Wearables as medical technologies are becoming part of personal analytics, measuring physical status, recording physiological parameters, or informing schedules for medication. ${ }^{20}$

The journey of wearables started with the invention of spectacles around the 13th century by English friar Roger Bacon. ${ }^{21}$ Growth in wearables was slow until the 20 th century, when in 1907, the first portable camera was put on the market. Since then, the pace of developing new devices never ceased to increase until 2014, when android wearables were commercialized. The whole evolution of wearable technology is picturesquely presented in the chronological sequence in Figure 1.

From a monetary perspective, the market of wearable devices is anticipated to grow exponentially at a rate of $20 \%$ and is expected to reach 150 billion EUR by 2028, as presented in Figure 2.

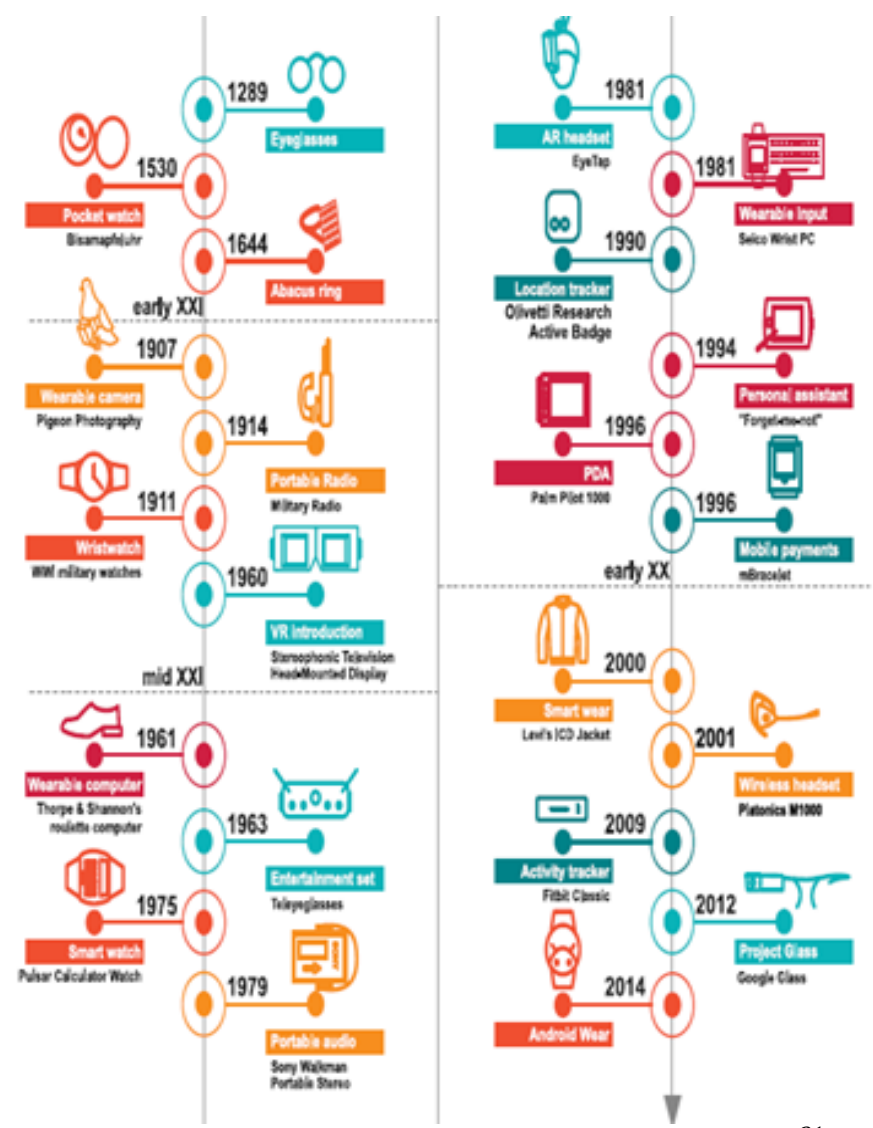

FIGURE 1. Evolutional milestones in wearable devices. ${ }^{21}$

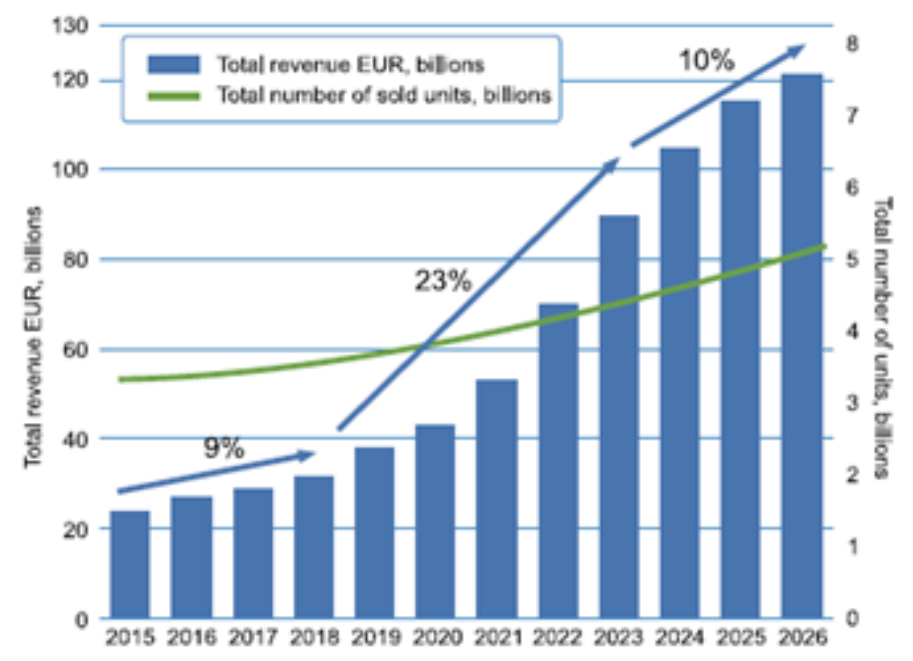

FIGURE 2. Wearable market growth forecast. ${ }^{21}$ 
In the third quarter of 2021, the Chinese market shipped 35.28 million units across the globe, ${ }^{22}$ and the market was dominated by Huawei. ${ }^{23}$ From a technological point of view, wearables are self-contained devices with embedded sensors worn by the user to detect, diagnose, monitor, and communicate the health and performance data of the user. ${ }^{24}$ Wearable technologies include smartwatches, wristbands, hearing aids, electronic/optical tattoos, head-mounted displays, subcutaneous sensors, Smart belts, electronic footwear (Smart shoes and socks), and Smart textiles (Smart pants, Smart shirts). ${ }^{20,25}$ Generally, wearables devices are composed of five components: sensors, connectivity, battery, interface, materials/algorithm. ${ }^{25}$ From the design and manufacturing consideration, wearable devices contains microprocessors, interface including data communication, different types of sensors: inertial measurement units (gyroscopes, accelerometers, barometers, and magnetometers), optical sensors (complementary metal-oxide-semiconductor [CMOS]) sensors, spectrophotometers, cameras, temperature sensors, chemical probes, electrodes, microphones, shock detectors, strain gauges. ${ }^{20}$

These days, when the world is dealing with COVID-19, vital-sign wearable solutions were implemented in different countries. Wearables can provide a key early-warning system about the likelihood of COVID-19 infection and its surveillance. ${ }^{26}$ For example, in Singapore, ViSi mobile developed by Sotera was used as a wearable device on patients in mild illness to monitor heart bit rate, respiratory rate, body temperature, and oxygen saturation. ${ }^{16}$

Wearable devices find different application in biomedical and clinical services, as shown in Figure 3.

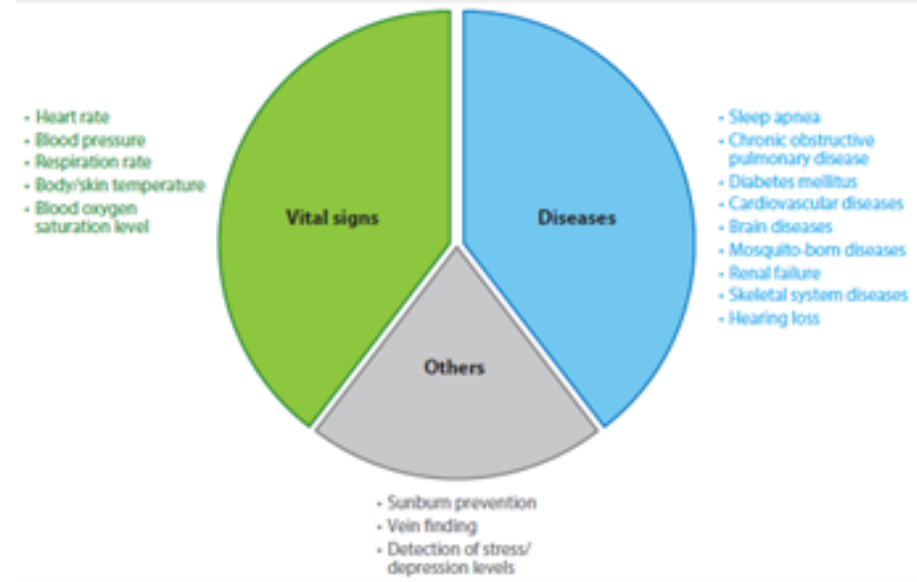

FIGURE 3. Some biomedical applications of medical wearables. ${ }^{27}$
Apart from measuring vital signs, aggregate data taken from wearables can also contribute to the research by detecting general patterns and trends within a population, contributing to improved public health responses. ${ }^{26}$ Wearables are positioned to different body parts depending on the parameter to be measured, as shown in Figure 4.

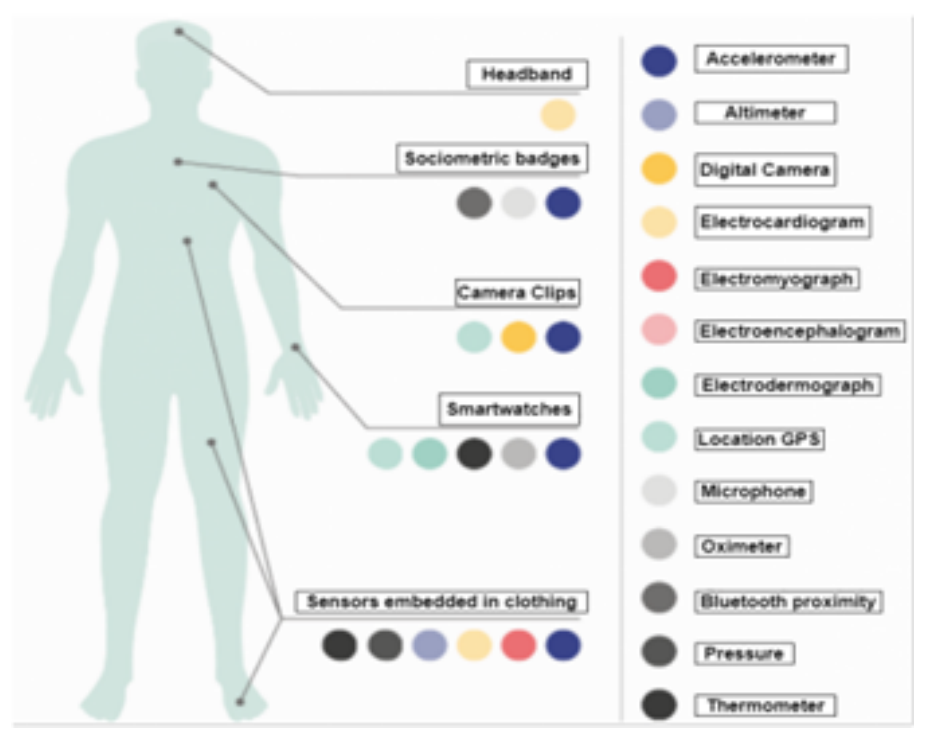

FIGURE 4. Wearables based on on-body location. ${ }^{26}$

Wearable devices come into 4 main classes ${ }^{25}$ :

- Lifestyle and fitness devices. This includes fitness trackers, sport and activity trackers (e.g., Moov Now, Misfit Shine, Fitbit charge2).

- Diagnostics and monitoring devices. These noninvasive devices provide valuable health information (e.g., DexcomG4, Quardio Core).

- Therapeutic devices. These devices monitor disease states, track activity, store data, and deliver feedback therapy (e.g., Quell, Minimed530GInsulin Pump).

Injury prevention and rehabilitation devices. This includes body motion monitoring devices, wearable sensing garments, fall detection devices (e.g., Philips lifeline, sprouting baby monitor).

The International Electro-technical Committee Standardization Management Board Strategic Group10 distinguishes wearable technologies into near-body electronics, on-body electronics, in-body electronics, and electronic textiles. ${ }^{17,21}$ Wrist-worn and handheld wearables are the most widely adopted and market-filled niche covering 
Smart rings, wrist bands, smartwatches, and gesture control devices. ${ }^{21}$

Unlike conventional testing in a clinical setting, which may occur a few (or less) times a year, wearables offer continuous access to real-time physiological data. ${ }^{28}$ In their use, wearable devices are applications of the Internet of things, a concept used by devices for sending and receiving data via the Internet. ${ }^{18}$ Embedded intelligence connectivity offers a unique opportunity for condition monitoring, localization, identification, personal contextual notifications, information display, and virtual assistance. ${ }^{21}$

The wearables data processing cycle follows 6 stages, as presented in Figure 5.

The wearable market is growing faster in patients with specific conditions like epilepsy, chronic obstructive pulmonary disease, asthma, heart arrhythmia, chronic pain, and breast cancer. ${ }^{17}$

Today, many wearable devices are commercially available, such as rings, headsets, sleep masks, wearable patches, arm straps, finger clips, chest straps, fitness bracelets, fitness bands, and flex garments. Specific products include Google Glasses, GOW Pack, LUMOback, Metria Wearable Sensor Technology, nECG Platform, Peeko Monitor, PERSmobile, NuMetrex Heart Sensing Racer Tank, Re-Timer, SleepShirt, T. Jacket, 360 Kids Guardian, and Vega. ${ }^{15,24,29}$

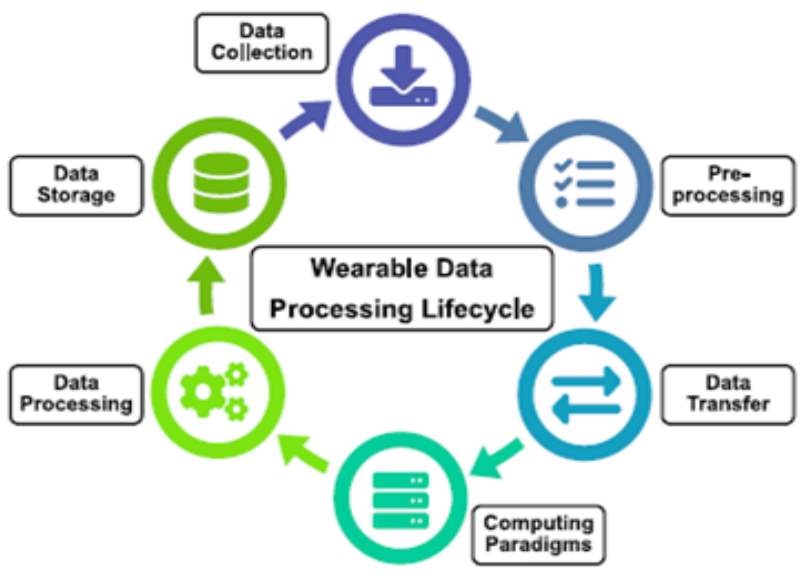

FIGURE 5. Wearables data processing cycle. ${ }^{21}$

Significant growth in purchased wearable devices has been recorded in North America, Western Europe, and the Asia Pacific region, while in the rest of the world, the market growth is lower. Reports about the future of wearable technologies predict that the market volume will be 27.8 billion dollars in 2022 and $93 .{ }^{19}$ billion dollars in $2027 .{ }^{18}$

Some of the challenges of wearable devices include the feeling of constant surveillance, inefficient data analytics, lack of appropriate data labeling, insufficient computing capabilities, inefficient switching among resources in hybrid networks, lack of modern energy harvesting

TABLE 2. Wearable Wireless Technologies, Operating Frequency, and Range. ${ }^{21}$

\begin{tabular}{|c|c|c|c|}
\hline & Communication Technology & Frequency Range & Range \\
\hline Short-range & RFID & $125-134 \mathrm{kHz}, 13.56 \mathrm{MHz}, 860-960 \mathrm{MHz}$ & Up to $100 \mathrm{~m}$ \\
\hline & NFC & $13.56 \mathrm{MHz}$ & $<0.2 \mathrm{~m}$ \\
& BLE (IEEE 802.15.1) & $2.4-2.48 \mathrm{GHz}$ & Up to $100 \mathrm{~m}$ \\
\hline & Zigbee Zigbee (IEEE 802.15.4) & $868-868.6 \mathrm{MHz}, 902-928 \mathrm{MHz}, 2.4-2.49 \mathrm{GHz}$ & $20-250 \mathrm{~m}$ \\
\hline & Wi-Fi (IEEE 802.11a/b/g/n) & $2.4-2.48 \mathrm{GHz}$, & Up to $70 \mathrm{~m}$ \\
\hline & Wi-Fi 5 (IEEE 802.11ac) & $4.9-5.8 \mathrm{GHz}$ & Up to $120 \mathrm{~m}$ \\
\hline & Wi-Fi 6 (IEEE 802.11ax) & $4.9-5.8 \mathrm{GHz}$ & $10-100 \mathrm{~m}$ \\
\hline & WiGig (IEEE 802.11ad/ay) & $1-6 \mathrm{GHz}$ & Up to $100 \mathrm{~m}$ \\
\hline & VLC (IEEE 802.15.7) & $57-70 \mathrm{GHz}$ & Up to $15 \mathrm{~km}$ \\
\hline & VLC (IEEE 802.15.7) & $400-800 \mathrm{THz}$ & Up to $10 \mathrm{~km}$ \\
\hline Long-range & LTE-M & LTE frequency bands & Up to $50 \mathrm{~km}$ \\
\hline & LoRa & LTE frequency bands & Up to $50 \mathrm{~km}$ \\
\hline
\end{tabular}


opportunities, low data resolution. ${ }^{21}$ The major market players in wearable medical technologies are: Apple, Fitbit, Jawbone, Misfit, Mykronoz, Samsung, Garmin Ltd, Xiaomi Technology Co. Ltd, Qualcomm Technologies, Inc; Adidas Group, Sony Corporation, Lifesense Group. ${ }^{18}$ The details on many body-worn devices are presented in Figure 6.

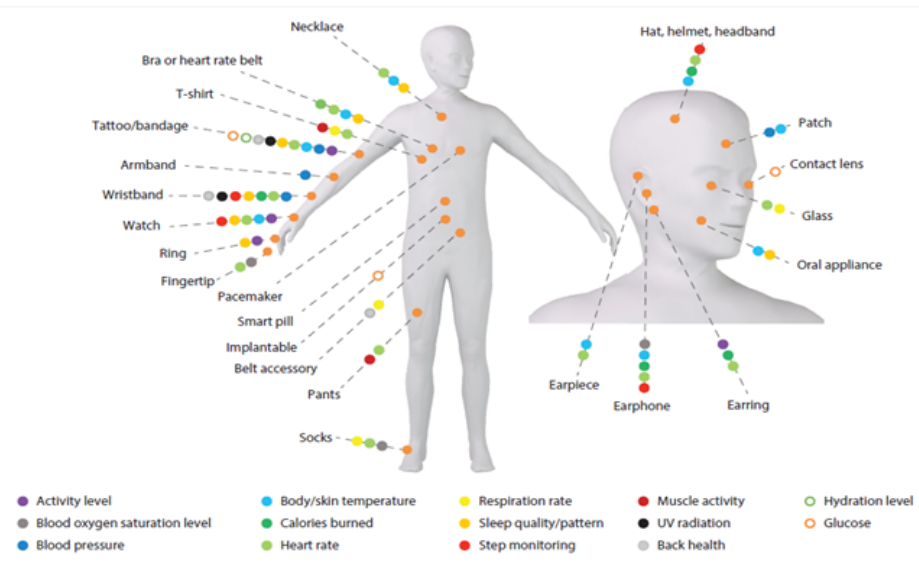

FIGURE 6. Wearable devices worn on various body parts and the parameters they can monitor. ${ }^{27}$

\section{Artificial Intelligence (Al)}

AI is rapidly evolving in clinical practice in dealing with a significant amount of data provided by Smart wearables, Smartphones, and other monitoring systems in medical services. ${ }^{6}$ The concept of AI was first conceived in 1950 by Alan Turing in his book entitled Computers and Intelligence in what was called Turing test when he was trying to determine whether computers were capable of human intelligence. In 1956, John McCarthy described "Artificial Intelligence" as the science and engineering of making intelligent machines. ${ }^{30}$ The systematic evolution of AI is presented in Figure 8. Today, AI is defined as using computers and technology to simulate intelligent behavior and critical thinking comparable to a human being or the science and engineering of making intelligent machines. ${ }^{31-34}$

The evolution of $\mathrm{AI}$ is presented in Figure 3. AI is not one type of machine or robot but a series of approaches, methods, and technologies that display intelligent behavior by analyzing their environments and taking actions-with some degree of autonomy - to achieve specific targets that can improve health services.35,36 Studies about AI have exponentially increased from 826 in 2012 to 12563 in 2019.37 By 2019 , there were 279,145 AI patent applications in the US, with the global market expected to reach 190.61 billion dollars in 2025. AI can add about $\$ 15.7$ trillion to the world economy by 2030,38 with China leading the global market in 2030 with a share of $26.1 \% .39$

These assertions are justified by the research article published by Chinese universities from 2015 to 2019, as seen in Figure 7.

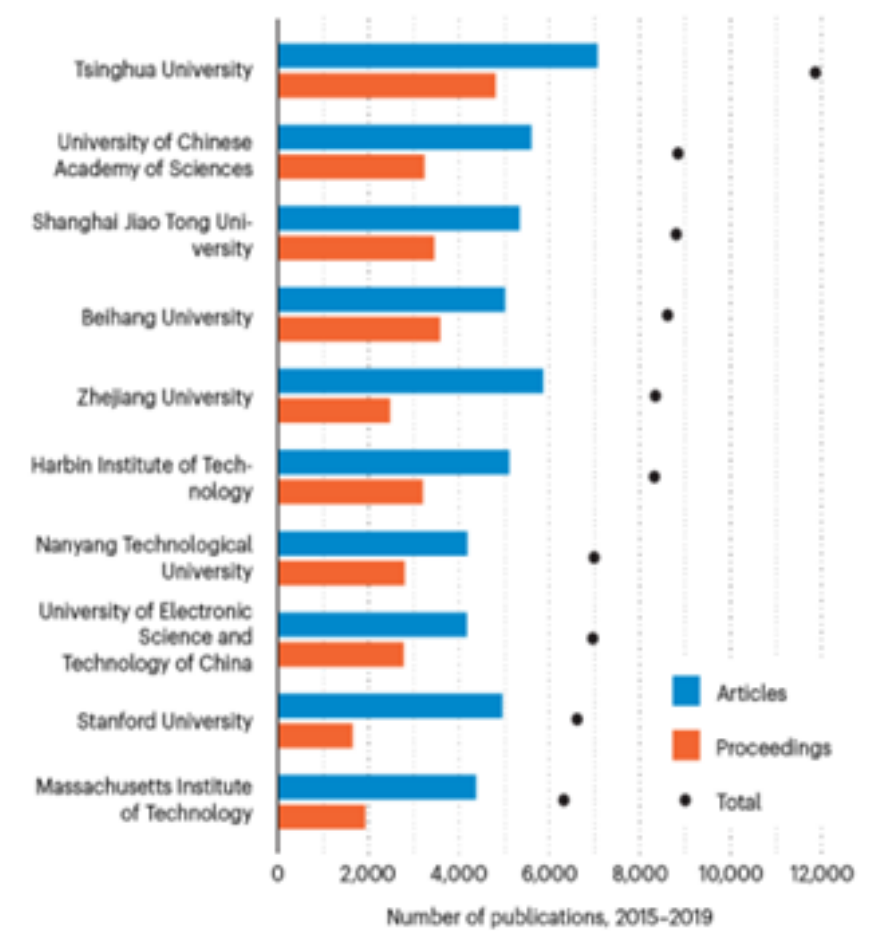

FIGURE 7. Top 10 institutions with the most AI-related publications (2015-2019). ${ }^{40}$

With AI, patients will receive more rapid, accurate diagnoses and reduced adverse events. The top applications of AI include robot-assisted surgery, virtual nursing assistant, administrative workflow assistance, fraud detection, dosage error reduction, clinical trial participant identification, preliminary diagnosis, automated image diagnosis, cybersecurity, health research, and drug discovery and development. ${ }^{41} \mathrm{AI}$ also finds application in diagnosis and case identification and prognosis and prediction.

The AI umbrella encompasses the following subfields ${ }^{30}$ :

- Machine learning (ML): Machine learning involves training an algorithm to perform tasks by learning from 
patterns in data rather than performing an explicitly programmed job. ${ }^{42}$ Machine learning algorithms can automatically learn and improve from experience without explicitly programming. The most common algorithms of ML are: supervised learning (used when we can precisely define the task we want the algorithm to learn based on data that we already have), unsupervised learning (It is like learning without a teacher. We have a group of patients with different sets of data, but we do not know their individual diagnoses. We build a model, then try to cluster patients based on similar attributes such as the symptoms they presented with, their lab markers or age and gender), Reinforcement Learning (this allows the algorithm to learn how to complete the tasks with a sequence of decisions by itself without being told how to do it). ${ }^{35,37}$

- Deep learning (DL): It is a subset of ML with similar functions but with different capabilities. ${ }^{37}$ This method of AI allows a machine to be fed with large quantities of raw data and to discover the representations necessary for detection or classification. ${ }^{43} \mathrm{DL}$ uses chips called graphics processing units to rapidly perform required calculations, a single card of which can potentially process hundreds of millions of images a day. ${ }^{42}$ DL mammography is used for breast cancer detection, in computed tomography (CT) for column cancer diagnosis, in chest radiographs, for the detection of pulmonary nodules. ${ }^{41}$

- Natural language processing: This branch of AI is concerned with the use of computational methods in understanding and interpreting human language. ${ }^{35,42}$ Artificial Neural Networks (ANN) or Simulated Neural Networks (SNN): ANN are considered the heart of DL. ANN is technology based on a human neural network. ${ }^{44}$ Examples of ANN include handwriting recognition, speech-to-text transcription, weather prediction, and facial recognition. ${ }^{45}$ An SNN contains a node layer, one or more hidden layers, and an output layer. Each node, or artificial neuron, connects to another and has an associated weight and threshold. If the output of any individual node is above the specified threshold value, that node is activated, sending data to the next layer of the network. ${ }^{46}$ ANN are used in economics, ecology, environment, biology. In medicine, the most widely used family is the multilayer perceptron (PMC) in therapeutic decisions to process data for anthropology. ${ }^{47}$

- Computer Vision (CV): CV allows the building of artificial systems capable of retrieving any information from an image previously obtained. CV involves different stages, namely: image acquisition (image capture with a sensor and transformation of visual information into digital information), pre-processing (preparing the image for the next level handling), feature extraction (detection of some objects to be analyzed), segmentation (separation of images into cohesive regions), noise reduction and high-level processing. ${ }^{48}$ Today, there are many practical applications where AI was successfully useful.

TABLE 3. Examples of Success of Artificial Intelligence. ${ }^{37}$

\begin{tabular}{|c|c|}
\hline Company & Application \\
\hline Babylon Health & $\begin{array}{c}\text { Software application for online consultation } \\
\text { where the system gives medication based on the } \\
\text { symptoms entered in the system }\end{array}$ \\
\hline $\begin{array}{c}\text { Sensely } \\
\text { (developed Molly } \\
\text { app) }\end{array}$ & $\begin{array}{c}\text { A virtual nurse that was designed to have a } \\
\text { smiling face coupled with a pleasant voice to } \\
\text { assist patients with monitoring their health }\end{array}$ \\
\hline $\begin{array}{c}\text { Deep Genomics } \\
\text { (developed } \\
\text { Oncecompass } \\
\text { Medecine app) }\end{array}$ & $\begin{array}{c}\text { To match genetic mutations found in patients } \\
\text { tumor samples with ongoing clinical trials } \\
\text { worldwide }\end{array}$ \\
\hline IBM Watson & $\begin{array}{c}\text { Software that provides evidence-based treatment } \\
\text { options for oncologists }\end{array}$ \\
\hline Atomwise & $\begin{array}{c}\text { Uses supercomputers to root out treatments from } \\
\text { a database of molecular structures }\end{array}$ \\
\hline
\end{tabular}

The key challenges of $\mathrm{AI}$ are their computing power, trust deficit, data privacy and security, data scarcity,38 ethical regulations, high resource and research cost, shortage of transparency, poor governance and accountability, notability of data annotation. ${ }^{49}$

Globally, the AI companies are NVIDIA Corporation, Amazon.com, Inc., Meta Platforms, Inc., DeepMind, OpenAI, Affectiva, DataRobot, Ubiquity6 CloudMinds. ${ }^{50,51}$ To ensure appropriate utilization of AI, companies need to embrace techniques that help them achieve fairness, security, and explainability. ${ }^{49}$ 
TABLE 4. Applications of Artificial Intelligence in Diagnosis and Prediction. ${ }^{43}$

\begin{tabular}{|c|c|c|c|}
\hline \multicolumn{3}{|c|}{ Diagnosis and case identification } & \multirow{2}{*}{ Prognosis and prediction } \\
\hline Function & Clinical area & Applications & \\
\hline \multirow{2}{*}{ Waveform analysis } & Obstetrics & Intrapartum monitoring & \multirow{8}{*}{$\begin{array}{l}\text { Cardiovascular risk prediction, } \\
\text { Prediction of breast cancer } \\
\text { survival. Prediction of outcomes } \\
\text { in colorectal cancer, Predicting } \\
\text { of survival in non-small cell } \\
\text { lung cancer. Prediction of } \\
\text { hospitalization due to heart } \\
\text { disease. Prediction of sepsis in the } \\
\text { intensive care unit, emergency } \\
\text { department, and hospital floor } \\
\text { Prediction of treatment outcome } \\
\text { in social anxiety. Prediction of } \\
\text { psychiatric readmission from } \\
\text { discharge summaries }\end{array}$} \\
\hline & Neurology & Remote monitoring of gait & \\
\hline \multirow{5}{*}{ Image processing } & Pathology & $\begin{array}{c}\text { Detection of lymph node metastases in breast } \\
\text { cancer }\end{array}$ & \\
\hline & Dermatology & $\begin{array}{l}\text { Identification of benign and malignant tumors, } \\
\text { identification of fungal infection, classification of } \\
\text { skin cancer }\end{array}$ & \\
\hline & Ophthalmology & $\begin{array}{l}\text { Identification of diabetic retinopathy, grading of } \\
\text { macular degeneration }\end{array}$ & \\
\hline & Cardiology & $\begin{array}{l}\text { Diagnosis of acute coronary syndrome, } \\
\text { identification of heart failure status through } \\
\text { remote patient monitoring }\end{array}$ & \\
\hline & Radiology & $\begin{array}{c}\text { Mammography, diagnosis of pneumonia from } \\
\text { chest x-ray }\end{array}$ & \\
\hline $\begin{array}{l}\text { Electronic health } \\
\text { records analysis }\end{array}$ & \multicolumn{2}{|c|}{$\begin{array}{l}\text { Identification of sepsis in the emergency department, Identification of breast } \\
\text { cancer symptoms, Heart failure case identification, Identification of patient } \\
\text { phenotype from analysis of intensive care unit data, identification of medical } \\
\text { subdomains in clinical notes }\end{array}$} & \\
\hline
\end{tabular}

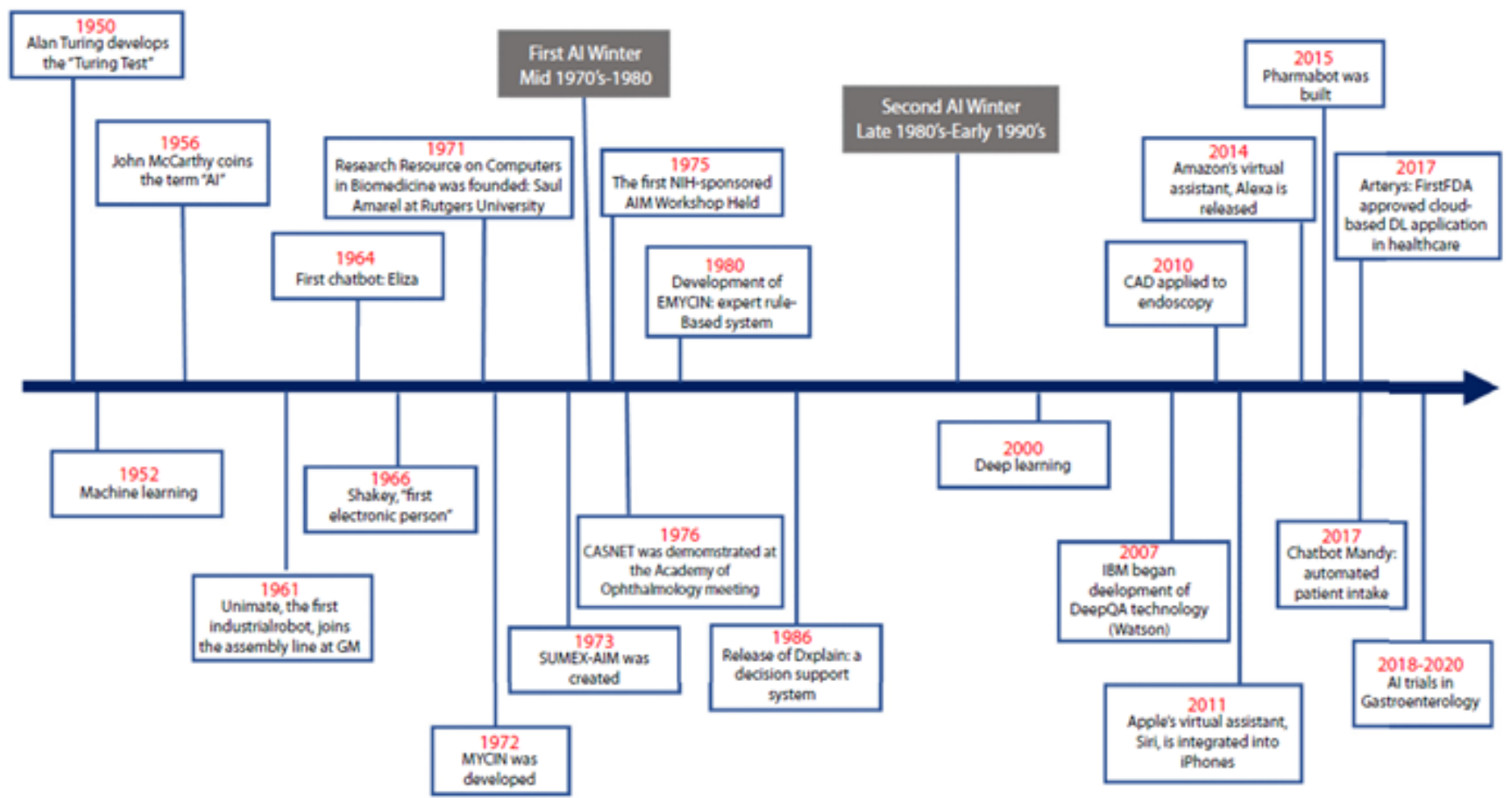

FIGURE 8. Historical evolution of artificial Intelligence. ${ }^{30}$ 


\section{BCT or DLT}

Patients and healthcare practitioners are faced with the challenge of accessing, managing, integrating, and sharing health records securely. ${ }^{52}$ In many countries data are recorded on legacy papers and numerous disconnected electronic systems. In the US, $90 \%$ of physicians use unconnected computerized systems. Patients must recount their history multiple times, which may be done incompletely. Medical errors are estimated to be the third leading cause of death for Americans. In 2015, 140 million patient records were breached according to Protenus Breach Barometer Report. ${ }^{53}$ The WHO estimates that many countries in Africa and parts of Asia and Latin America have areas where more than $30 \%$ of the medicines on sale can be counterfeit. ${ }^{54}$

In 2018, the healthcare industry continued to be plagued by data breaches involving sensitive patient information. According to the Breach Barometer 2019 Report, more than 15 million patient records were breached in 2018 . Such incidents allow blockchain vendors to launch new solutions. ${ }^{54}$

To alleviate the associated adverse effects, an interconnected system is needed. In the UK, the NHS planned to interconnect all computerizing health network records by 2018; however, this target was delayed first to 2020 and again to 2023. ${ }^{55}$ Nevertheless, during COVID-19, which is ravaging the globe, blockchain technology was used by two UK hospitals to keep tabs on the storage and supply of temperature-sensitive COVID-19 vaccines. ${ }^{56}$

In March 2021, Moderna, a biotechnology and pharmaceutical company based in the United States, signed a new agreement with IBM to use blockchain technology to manage its COVID-19 vaccines. Additionally, 3M Pharmaceuticals, another American pharmaceutical giant, uses blockchain technology to curb counterfeit pharmaceuticals. Recently, it has started using blockchain technology to identify and stop counterfeit face masks. ${ }^{57}$

BCT, though initially designed for the financial market, its inherent characteristics make it suitable for the health sector, insurance, pharmacy, IoT, food science, industries, e-voting, tourism, energy, and legal contract. ${ }^{58-60}$ BCT helps streamline business processes by establishing trust, accountability, and transparency. ${ }^{58}$ In medical applications, the ideal blockchain model would be scalable with high security and data privacy. In finance, bitcoin and Ethereum are examples of cryptocurrencies that use blockchain technology. ${ }^{61}$

In medical and clinical services, by using BCT, patients become the platform, owning and controlling access to their healthcare data. The data are stored in the private blockchain cloud, where they cannot be changed by anybody, including physicians and patients themselves internally and natively.

Because data is stored on a decentralized network, there is no single institution that can be robbed or hacked to obtain a large number of patient records. Data is encrypted in the blockchain and can only be decrypted with the patient's private key. Even if a malicious party infiltrates the network, there is no practical way to read patient data. ${ }^{62,63}$

In terms of patients' full control of their health record history, there are three major aspects of privacy that need to be considered: (a) data ownership; (b) fine-grained access control; (c) data transparency, integrity, and auditability. ${ }^{53}$

In healthcare services, the key enablers of blockchain are the need for patient data security, desire to reduce medical errors and mistakes, breakthroughs in genomics, drug traceability and safety, government partnerships, removal of unscrupulous attacks, reduction of cost in medical transactions, and improved confidentiality in healthcare business operations. ${ }^{63}$

A blockchain is a ledger of transactions where an identical copy of the ledger is visible to all the members of a computer network. It is a digital healthcare system management from which authorized users, such as providers and patients, have access. ${ }^{62}$ BCT is a permanent record of online transactions distributed, shared, and maintained by multiple parties.

The first blockchain was developed by Satoshi Nakamoto in 2009. The technology brought breakthroughs until 2021 when Dubai hosts all government operations and record-keeping operations on blockchain as part of the Smart Dubai 2021 initiative. $^{64}$ 


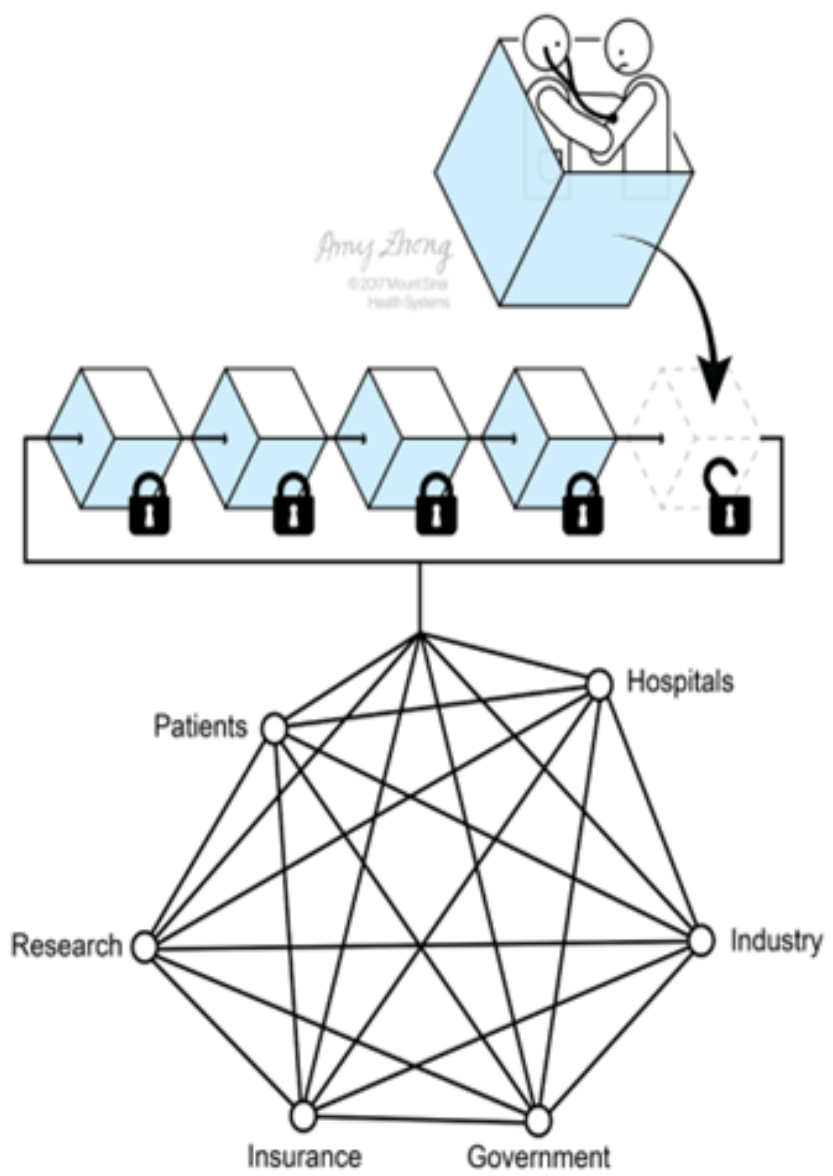

FIGURE 9. Theoretical schematic of blockchain technology in healthcare. ${ }^{59}$

The data-sharing practice is essential to enable clinical practitioners to transfer their patients' clinical data to the concerned authority for a quick follow-up. ${ }^{60}$ BCT differs from a personal ledger in the number of security checks, whereby a blockchain makes many security checks. ${ }^{61}$ This technology is interpreted as blocks linked together to form a chain to offer patients and caregivers the ability to securely share the patient identity and healthcare information across platforms.

Today, the market for blockchain technology is very promising because it is forecast to save $\$ 100$ billion per year since 2025 . The saving will be realized in a reduction in data-breaching related costs, operations costs, information technology (IT) costs, counterfeit-related fraud, and insurance fraud. ${ }^{52}$ In healthcare, the blockchain market in healthcare was valued at USD 2.12 billion in 2020 and is expected to reach USD $3 .{ }^{49}$ billion by 2026 and USD 4.7 billion in 2027 with a CAGR of $8.7 \%$ during the forecast period, 2021-2026, with North America as the fastestgrowing market. ${ }^{54}$ Regarding research, the number of scientific publications about blockchain technology shifted from 5 in 2016 to 64 in 2018. This was another indicator that this market was rapidly attracting researchers. ${ }^{65}$ In its structure, the components of blockchain technology are listed below.

- Blocks are the base of a blockchain and contain records linked lists, chains, genesis blocks, and consensus protocol. ${ }^{66}$ Blocks contain records of the past transactions and have segments reserved to save the data for future transactions. A block on a blockchain network consists of hash codes, root hash of merkle tree, and nonce. ${ }^{61}$

- Chains are blocks inside a blockchain network that are connected to each other. Multiple blocks that are joined together form a chain of blocks.

- Nodes contain the entire history of a blockchain network. Nodes are the devices that store these vast amounts of data. Computers, laptops, and big servers function as nodes. All the nodes in a blockchain network are linked together. Nodes verify the signatures, double-check the answer of the hash code after authenticating the details, and add a new block to the blockchain network. Nodes can stay both online and offline. ${ }^{61}$

- Master nodes. Selective blockchain networks have master nodes which are are more capable than normal nodes. ${ }^{61}$

- Peer-to-peer networks (P2P) are networks designed for linking two nodes.

There are four types of blockchains:

- Public blockchains are permissionless blockchains that allow anyone to join. All nodes of the blockchain have equal rights to access the blockchain, create new blocks of data, and validate blocks of data. ${ }^{58,67}$

- Private or managed blockchains are permissioned blockchains controlled by a single organization. In a private blockchain, the central authority determines who can be a node. The central authority also does not necessarily grant each node with equal rights to perform functions. ${ }^{67}$ 
- Consortium blockchains are permissioned blockchains governed by a group of organizations, rather than one entity. However, setting up consortiums can be a fraught process as it requires cooperation between several organizations presenting logistical challenges and potential antitrust risks. ${ }^{67}$

- Hybrid blockchains are controlled by a single organization, but with a level of oversight performed by the public blockchain, which is required to perform specific transaction validations. ${ }^{67}$

Some key players in the blockchain market are IBM Corporation, Microsoft Corporation, Gem, Patientory Inc., Guardtime Federal, Isolve, and Factom ${ }^{57}$

TABLE 5. Challenges of Blockchain Technology 59,62,60

\begin{tabular}{|c|c|}
\hline Technology & $\begin{array}{c}\text { Blockchain software is still in its infancy, } \\
\text { continually being developed and refined }\end{array}$ \\
\hline Integration & $\begin{array}{c}\text { Must initially be co-existent with current } \\
\text { technologies, must be integrated overtime }\end{array}$ \\
\hline Cost & $\begin{array}{c}\text { Adoption of new technologies will incur } \\
\text { initial greater costs to institutions }\end{array}$ \\
\hline Regulation & $\begin{array}{c}\text { Government institutions have yet to settle } \\
\text { regulatory concerns over blockchain } \\
\text { technology }\end{array}$ \\
\hline Culture & $\begin{array}{c}\text { Adoption of the technology will require } \\
\text { significant buy-in from the global } \\
\text { community }\end{array}$ \\
\hline Energy & $\begin{array}{c}\text { Maintaining the blockchain requires a } \\
\text { network of nodes, and resulting substantial } \\
\text { computing power }\end{array}$ \\
\hline Privacy & $\begin{array}{c}\text { Emerging cyber security concerns must be } \\
\text { addressed before individuals will entrust } \\
\text { data to a public blockchain }\end{array}$ \\
\hline
\end{tabular}

\section{Robotics Technology}

Technological advancement has revolutionized how medical procedures take place, including surgical operations. Credits go not only to the development of actuators, sensors, control systems, and materials but also to the growth of imaging systems for medical applications such as higher resolutions and magnetic imaging. ${ }^{71}$ Apart from the industrial robot (a word originating from the Czech word "robota" meaning compulsory labor) first developed
50 years ago, today's medical and healthcare robots are used in tremendous clinical work. ${ }^{72,73}$

According to the Robotic Institute of America, a robot is a machine in the form of a human being that performs the mechanical functions of a human being but lacks sensitivity. The first robot was developed by Leonardo Da Vinci in 1495, purposed at amusing royalty. It was followed the creation of the first operational robot by Joseph Marie Jacquard in 1801, in which an automated loom, controlled by punch cards, created a reproducible pattern woven into cloth. ${ }^{73}$

In medicine, robotic systems were first introduced in the mid-80s, and today they make an impact in various medical disciplines, including general surgery, research, therapy, rehabilitation, neurosurgery, orthopedic surgery, ${ }^{74}$ and medical transport (for example, TUG Robot able to carry around more than 400 kilograms of medication). ${ }^{75}$

As per $2017,20 \%$ of the world population experience difficulties with physical, cognitive, or sensory functioning mental and behavioral health, which can be solved with robotics technology application. ${ }^{76}$ The very first mechanical robot to be used in surgery was the Puma 560 in 1985 for the precise positioning of the cannula for brain biopsies. ${ }^{77}$

Statistics show that 1 in every 25 patients will contract hospital-acquired infection (HAIs) in the USA, and 1 in 9 will die. ${ }^{75}$ That is why next-generation smart hospitals have robotics that can help reduce infections, viruses, and bacteria. ${ }^{78}$ For example, Xenex Robot allows for fast and effective systematic disinfection of any space within a healthcare facility by destroying deadly microorganisms causing HAIs using special ultraviolet (UV) disinfection methodology. ${ }^{75}$ Data from the USA show that surgery costs annually are estimated to be $\$ 170$ billion, with an estimated $\$ 41$ billion US spent on readmission due to complications. In Europe. over half (52\%) of all surgeries were due to unexpected complications. Consequently, robotics can lower the readmission rate by up to $50 \%$, resulting in a saving of $\$ 10$ billion annually. ${ }^{79}$ The global landscape of robotics application in healthcare and wellbeing are presented in Table 7. 


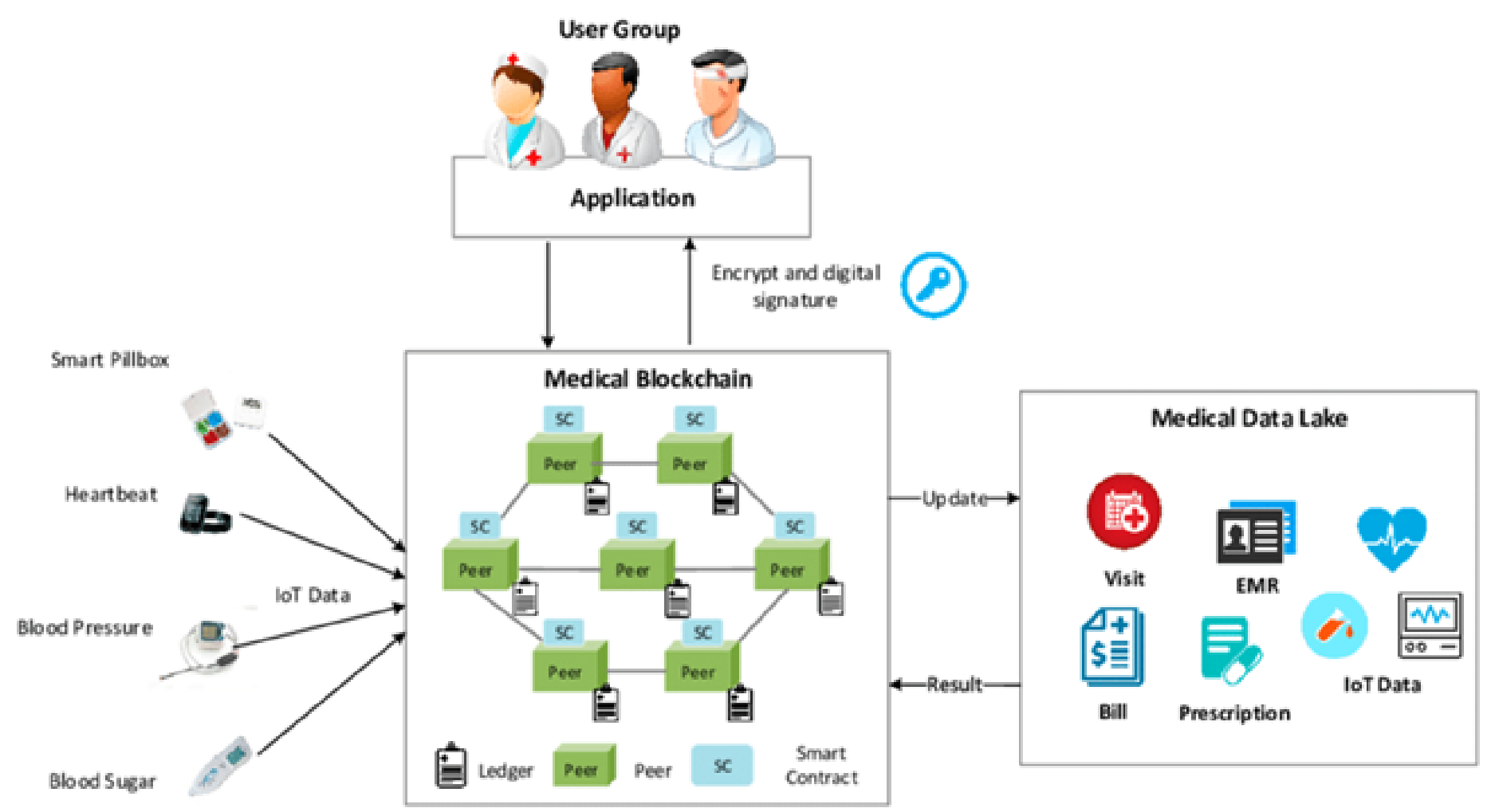

FIGURE 10. Blockchain structure in hospital applications. ${ }^{68}$

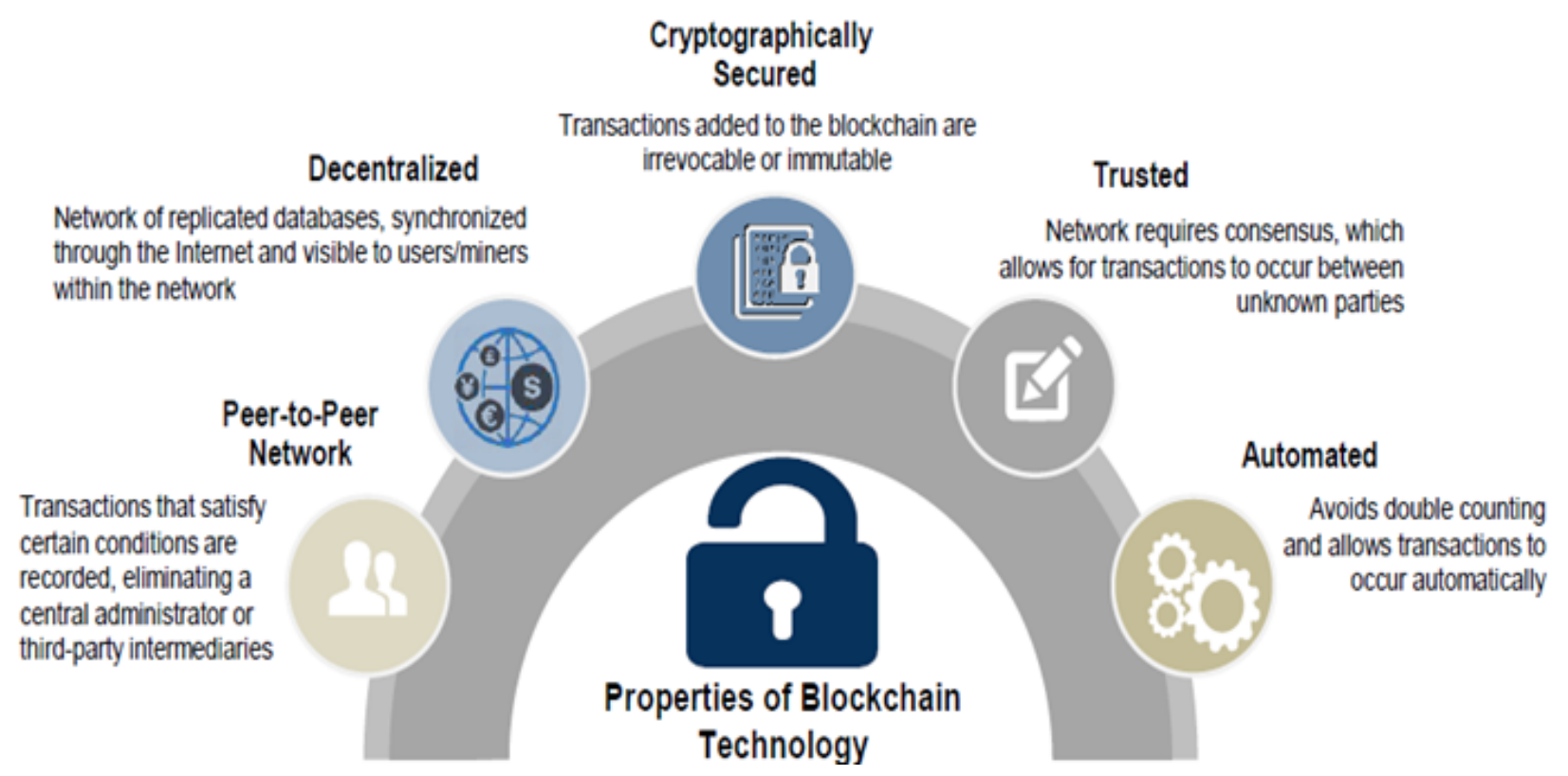

FIGURE 11. Properties of blockchain technology ${ }^{69}$ 
TABLE 6. Blockchain Potentials for Healthcare and Life Science ${ }^{52,59,70}$

\begin{tabular}{|c|c|c|}
\hline Category & Potential use & Key Benefits \\
\hline Patients & $\begin{array}{l}\text { Patient empowerment. Patients can keep track } \\
\text { of their medical background. Patients can check } \\
\text { their latest medical prescriptions, Patients can } \\
\text { share their data securely across their providers }\end{array}$ & $\begin{array}{l}\text { Increases patient trust. Improves patient access to trusted } \\
\text { data. Facilitates better collaboration, Increases transparency. } \\
\text { Improves and personalizes the patient experience. Increases } \\
\text { efficiency and reduces operations costs, Enables patient access } \\
\text { to their health records anywhere in the world. Enables patient } \\
\text { access to their latest prescriptions }\end{array}$ \\
\hline $\begin{array}{l}\text { Regulation and } \\
\text { compliance }\end{array}$ & $\begin{array}{c}\text { Compliance tracking, Smart contract-based } \\
\text { check }\end{array}$ & $\begin{array}{c}\text { Establishes a trusted audit trail verifiable in real-time. } \\
\text { Establishes a platform to enforce privacy regulations } \\
\text { automatically. Enables monitoring of who has shared data and } \\
\text { with whom, without revealing the data itself }\end{array}$ \\
\hline $\begin{array}{l}\text { Inter-company } \\
\text { processes }\end{array}$ & $\begin{array}{l}\text { Transfer of funds. Medical devices supply chain. } \\
\text { Temperature-controlled supply chains, Services }\end{array}$ & $\begin{array}{l}\text { Facilitates automated payments through smart contracts. } \\
\text { Increases speed for payments. Provides full transparency of } \\
\text { assets across the supply chain to the patient. Enables certified } \\
\text { \& private messaging between medical devices and service } \\
\text { providers. Brings all transactions into a single platform }\end{array}$ \\
\hline $\begin{array}{l}\text { Administration and } \\
\text { back offices }\end{array}$ & Revenue management & $\begin{array}{l}\text { Improves efficiencies in tracking and tracing areas where } \\
\text { leakage occurs. Reduces admin costs, Increases reliability and } \\
\text { auditability. Speeds up financial transactions process }\end{array}$ \\
\hline Pharmaceuticals & $\begin{array}{l}\text { Verifies drug provenance. Creates an industry- } \\
\text { wide, single source of aggregate information }\end{array}$ & $\begin{array}{l}\text { Tracks and traces pharmaceuticals, Proof of authenticity for } \\
\text { anti-counterfeiting techniques. Helps prevent the transport } \\
\text { and sale of counterfeit products. Makes it is possible to detect } \\
\text { the full spectrum of complications related to pharmaceutical } \\
\text { treatment }\end{array}$ \\
\hline $\begin{array}{l}\text { Research and } \\
\text { development }\end{array}$ & Securing clinical trials & $\begin{array}{l}\text { Prevents theft of intellectual property. Enables users to } \\
\text { authenticate any document and ensuring proof of the existence } \\
\text { Enables access to a huge anonymous and authenticated } \\
\text { database of patients }\end{array}$ \\
\hline
\end{tabular}

In their general design and construction, medical robots consist of a Central Processing Unit (the robot's brain for coordinating all its activities) and Sensors (acting as the powerhouse of the robot feedback mechanism). These include light sensors, sound sensors, temperature sensors, contact sensors, proximity sensors, distance sensors, pressure sensors, positioning sensors, etc.). Also included are Actuators (the robot's hydraulic, pneumatic, or electric muscles), End-Effectors (the tools that perform the actual work and interact with the environment or a workpiece), the Power Supply (energy required for robot operation), and the Program (for providing the logic that drives the robot behaviors and activities) ${ }^{81}$

Robotics applications in medicine involve different stakeholders, including primary stakeholders (direct robot user, clinicians, and caregivers), secondary stakeholders (robot makers, environmental service workers, health administrators), and tertiary stakeholders (policy makers, insurers, advocacy groups) ${ }^{76}$ Among robotics applications, surgical robots have a high revenue growth market segment, are highly competitive with established players, well-defined market entry routes, and a good product innovation pipeline. ${ }^{80}$

In 2020, the leading global company in medical robotics was Intuitive Surgical, with a market cap of $\$ 121$ billion, 6335 robots in service, ${ }^{78}$ with more than 1.2 million procedures performed globally, and with a growth of $18 \%$ per year. $^{80}$ 
Nkurunziza, JUdahemuka, Dusenge, Umutesi : Overview of Trending Medical Technologies

TABLE 7. Medical Robotics Market Potential Assessment Summary ${ }^{80}$

\begin{tabular}{|c|c|c|c|c|c|c|c|}
\hline \multicolumn{3}{|c|}{ Healthcare robotics } & \multicolumn{2}{|c|}{$\begin{array}{c}\text { Technology } \\
\text { Readiness level }\end{array}$} & \multirow{2}{*}{$\begin{array}{l}\text { Breadth of } \\
\text { application }\end{array}$} & \multirow[t]{2}{*}{ Current adoption } & \multirow[t]{2}{*}{ Growth potential } \\
\hline \multirow{2}{*}{ Medical robots } & \multicolumn{2}{|c|}{$\begin{array}{l}\text { Surgical } \\
\text { Robots }\end{array}$} & & & & & \\
\hline & \multicolumn{2}{|c|}{$\begin{array}{l}\text { Diagnostics } \\
\text { Robots }\end{array}$} & & & & & \\
\hline \multirow{4}{*}{$\begin{array}{c}\text { Healthcare Service } \\
\text { robots }\end{array}$} & \multicolumn{2}{|c|}{$\begin{array}{l}\text { Medication delivery and } \\
\text { dispensing }\end{array}$} & & & & & \\
\hline & \multicolumn{2}{|c|}{ Cleaning and disinfecting } & & & & & \\
\hline & \multicolumn{2}{|c|}{$\begin{array}{c}\text { Telepresence and remote } \\
\text { monitoring }\end{array}$} & & & & & \\
\hline & \multicolumn{2}{|c|}{ Autonomous vehicles } & & & & & \\
\hline \multirow{2}{*}{ Care robots } & $\begin{array}{l}\text { Person } \\
\text { Compa }\end{array}$ & $\begin{array}{l}\text { l assistant/ } \\
\text { hion robots }\end{array}$ & & & & & \\
\hline & \multicolumn{2}{|c|}{ Assistive robots } & & & & & \\
\hline $\begin{array}{l}\text { Predominantly } \\
\text { R\&D and } \\
\text { prototype phase } \\
\text { Technology De }\end{array}$ & $\begin{array}{l}\text { Several } \\
\text { Commercial } \\
\text { Products } \\
\text { Iopment }\end{array}$ & $\begin{array}{r}\text { Low, Specific } \\
\text { Breadth of }\end{array}$ & High, Mu & & Irrent Adoption & $\begin{array}{l}\text { Low } \\
\text { Gr }\end{array}$ & wth Potential \\
\hline
\end{tabular}

Other companies in service include Boston Dynamics, Stryker, Accuracy, Vicarious Surgical, Medtronic, GE Healthcare, Myomo, Stereotaxis, Ottava ${ }^{77,78}$ Neocis.Inc, Medtronics, Brainlab, Smith \& Nephew plc, Corindus Vascular Robotics, Inc., Riverfield Co., Ltd, Auris Health, Inc., etc. ${ }^{80}$

Between 2015-2020, China emerged as a leader for next-generation surgical robotic systems' innovations with 237 (36.5\%) patents published in this area from 2015 to 2020 (Figure 12). ${ }^{80}$
Top Patent Filings by Region, 2015$2020^{*}$

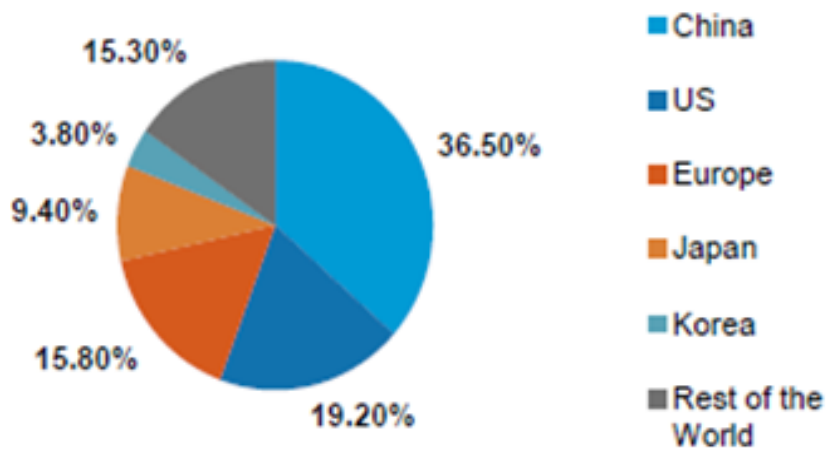

FIGURE 12. Medical robotics patent filings from 2015 to $2020 .^{80}$ 
The global medical robot market is expected to reach USD 12.7 billion by 2025 from an estimated USD 5.9 billion in 2020 at a CAGR of $16.5 \%$ during the forecast period. On the other hand,82 medical robotics market is forecast to account for $\$ 43.22$ billion in 2028 with a compound annual growth rate of $22.3 \%$ from 2021 to 2022 (Figure 13). ${ }^{82}$

\section{Global Medical Robots Market is Expected to Account for USD 43.22 Billion by 2028}

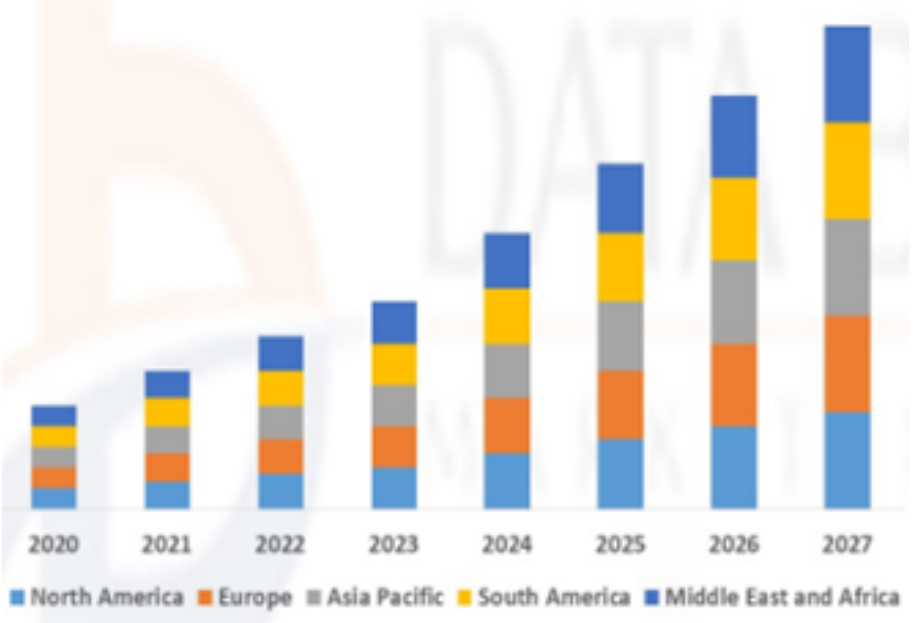

FIGURE 13. Market growth for medical robotics. ${ }^{82}$

The key drivers of medical robotics market evolution include demand for minimally invasive procedures for diagnosis, improved precision in diagnosis and treatment, technological advancement in AI, management of surge capacity during peak demand, and improvement of the overall efficiency of logistics. Also, there is a desire to increase the automation of pharmacy operations, large population living with chronical illnesses, hospitals' will to maintain hygiene protocols and standards, especially as it directly impacts hospital accreditation, reduces manual labor, improves efficiency and cost savings for cleaning and disinfection. Increasing prevalence of stroke, multiple sclerosis, Parkinson's disease, cerebral palsy, Rise of the elderly population, and shortage of caregivers. ${ }^{80}$

Nowadays, since 2019 when the whole world experienced the COVID-19 outbreak, robotics has been finding applications in undertaking human-like activities. ${ }^{83}$ In
Rwanda, robots were deployed to minimize contact time with confirmed cases and reduce the risk of contamination of health professionals in COVID-19 treatment centers. The 5 human-size robots are programmed to perform temperature screening, take vitals readings, deliver video messages, detect people not wearing masks, and then instruct them to wear masks properly. One robot called Urumuli deployed at Kigali International Airport had the capacity of screening 50 to 150 people per minute and reporting abnormalities to officers on duty. ${ }^{84}$

Later, on 9 February 2021, in partnership with the United Nations Development Programme, the government deployed another set of three THOR UVC robots to Nyarugenge District Hospital to strengthen the national response to COVID-19 pandemic. ${ }^{85}$ Robots were also used to store patients' data during diagnosis and treatment, reduce the workload of healthcare providers, ease the diagnosis procedures, and assist the physicians and students in learning more about the new disease in a short time. ${ }^{86}$

In South Korea, a self-driving robot with cameras and an LED screen was used to greet clients at the country's biggest mobile operator, check their temperatures, dispense hand sanitizers, and disinfect the floor. Other robots were used to disinfect 33 square meters in $10 \mathrm{~min}$ using ultraviolet radiation. In addition, they could detect people's gatherings, advise them to disperse, and wear face masks. ${ }^{87}$ In China, Wuhan City, where the pandemic was first detected, constructed a fully robot-staffed hospital where patients entering were screened by connected $5 \mathrm{G}$ thermometers to alert staff for feverish. In addition, Patients wore smart bracelets and rings that synced with Cloud Minds' AI platform so their vital signs, including temperature, heart rate, and blood oxygen levels, could be monitored. Doctors and nurses also wore the devices to catch any early signs of infection. ${ }^{88}$ Regarding the future of medical robotics, up to 2013, Nanorobotics was still the largely hypothetical technology of creating machines or robots at or close to the scale of a nanometer. ${ }^{73}$

Though the growth of the medical robotics industry is promising, it is humped by the following challenges: high establishment cost, fewer trained professionals to administer the tests, technical complexities leading to operational issues, the high running cost for disadvantaged people. ${ }^{80}$ 


\section{Nanomedical Technology}

It is a technology for diagnosing, treating, and preventing disease and traumatic injury, relieving pain, preserving and improving human health using molecular tools and molecular knowledge of the human body. ${ }^{89}$ Nanotechnology classically refers to the matter in a size range of 1-100 $\mathrm{nm}$ but can be extended to include materials below $1 \mu \mathrm{m}$ in size. ${ }^{90}$ Nanomedicine is also defined as the application of nanobiotechnologies to medicine. ${ }^{91,92}$

Though the concept of nanotechnology dates to 1959, the optimistic expectation of nanoparticles and nanoscale tools to improve the diagnosis and pharmacological treatment of several diseases was first established in $1990 .^{93}$ The basis of this new science derives from the development of an array of ultramicroscopic devices and the studies of cellular, molecular, and finally atomsized structures in biology, chemistry, and physics in the 20th century. Nanotechnology is not in itself a single emerging scientific discipline, but rather a meeting of different traditional sciences linking physics, chemistry, biology, medicine, electronics, and IT. ${ }^{94}$ Nanotechnology in medicine was recently focused on because there is a diversity of diseases originating from the alteration in biologic processes at the molecular level like mutated genes, misfolded proteins, and infections caused by viruses or bacteria (Figure 14). ${ }^{95}$ The three main subsections of nanomedicine are: nanobiotechnology, nanotechnology, and nanobiomimetics. ${ }^{96}$

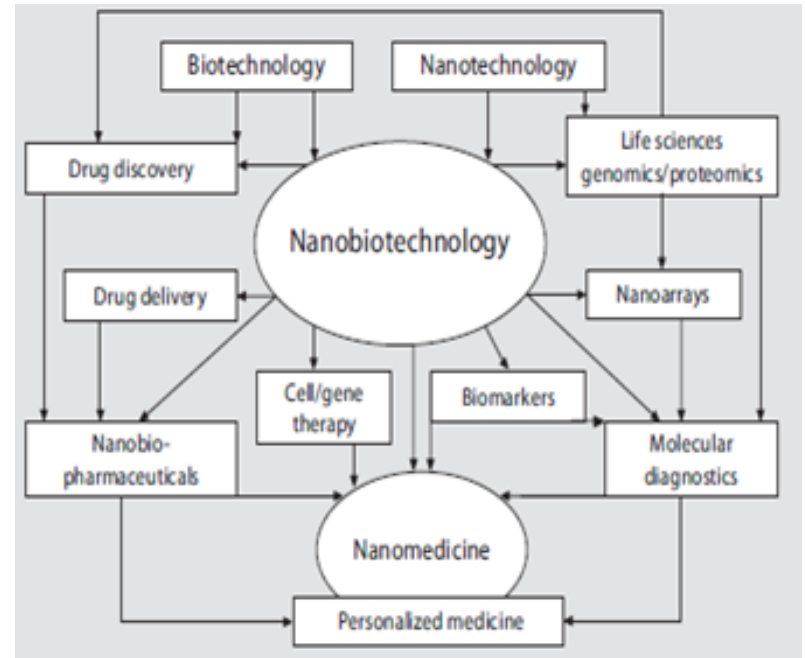

FIGURE 14. Relationship of nanobiotechnology to nanomedicine and other biotechnologies. ${ }^{91}$
Currently, in medicine, nanotechnology is used in antibacterial treatment, wound treatment, cardiovascular diseases, ophthalmology, cancer-fighting, cell repair, imaging, probing of DNA structure, tissue engineering, tumor detection, separation and purification of biological molecules and cells, MRI contrast enhancement and phagokinetic studies, company directory and to deliver drugs, heat, light or other substances to specific types of cells (such as cancer cells). ${ }^{91,97}$ Its use in diagnostics is at the development stage. The use of nanoparticles will reduce damage to healthy cells in the body and contribute to the early detection of diseases. ${ }^{91}$ The global Nanomedicine market size is projected to reach USD 232 million by 2026, from USD 150 million in 2019, at a CAGR of 6.4\% during 2021-2026. ${ }^{98}$

The nanomedicine market segmentation by type includes:

- Quantum dots (QD): QD are semiconductor nanocrystals that have a reactive core (made of cadmium selenide CdSe, cadmium telluride [CdTe], indium phosphide [InP], or zinc selenide [ZnSe]), for controlling their optical properties. QD are used in medical real-time tissue imaging, ${ }^{99}$ biological probes, for live cells labelling, ${ }^{100}$ drug delivery vehicles, in vivo imaging, therapeutic delivery, ${ }^{101}$ blood cancer assay, and cancer detection and treatment, in vivo animal targeting, tracking different particles, forecasting of disease stage. ${ }^{102}$

- Nanoparticles: A considerable fraction of the solid matter on earth can be found in the size range of colloids and nanoparticles, and in the last 2 decades, scientists have shown that colloids and nanoparticles are present everywhere in the environment. ${ }^{103} \mathrm{NPs}$ are categorized into three types: natural nanoparticles, incidental nanoparticles, and engineered nanoparticles (Figure 15). ${ }^{104}$

From a chemical point of view, nanoparticles are classified into inorganic and organic types. Inorganic nanoparticles are used as antimicrobial agent against bacteria, fungi, parasites, and viruses. ${ }^{104}$ Organic nanoparticles prepared from various materials, including polymers and lipids, have found exciting therapeutic delivery and imaging applications. ${ }^{105}$ 


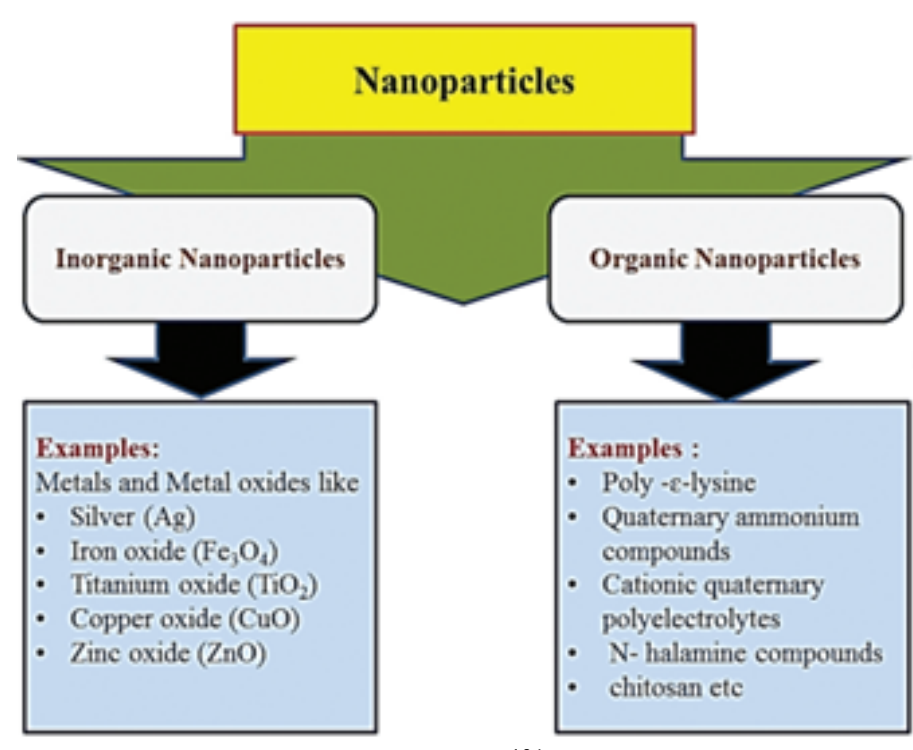

FIGURE 15. Types of nanoparticles. ${ }^{104}$

The choice of material impacts various properties, including drug encapsulation, immunogenicity, and targeting. At the same time, the design of nanoparticles, such as size, shape, flexibility, and compartmentalization, will also impact nanoparticle performance. These two attributes (choice of material and nanoparticle design) collectively determine the therapeutic outcome (Figure 16). ${ }^{105}$

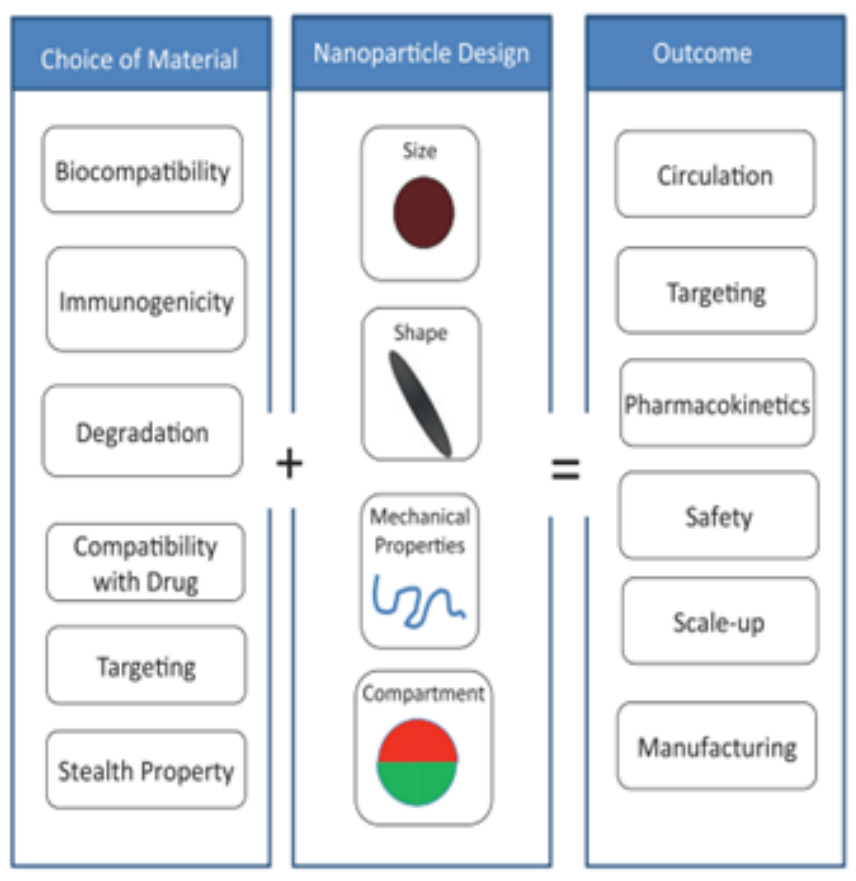

FIGURE 16. Design parameters for nanoparticles. ${ }^{105}$
Other applications of nanoparticles within medicine include tissue engineering, bio-micromechanical systems (bioMEMS), biosensors, anticancer drugs, microfluidics, and diagnostics. ${ }^{106}$

- Nanoshells: The discovery of nanoshells was made by Professor Naomi J. Halas and her team at Rice University in $2003 .^{107}$ These are a special class of nanomaterials that consist of concentric particles. ${ }^{108}$ A nanoshell is a type of nanoparticle with a dielectric (e.g., silica) core and a thin metal coating (usually gold). ${ }^{109}$

Nanoparticles find a place in medicine because of their safety, biocompatibility, stability, bioavailability, optically tunable, and photo-luminescent ability as well as high ability to attach to many therapeutic materials. Nanoshells (and especially gold nanoshells) show promise application in biomedical imaging, target therapy, gene delivery, tissue welding, drug delivery systems, therapeutic applications in general, and cancer imaging and treatment (Figure 17). ${ }^{110}$

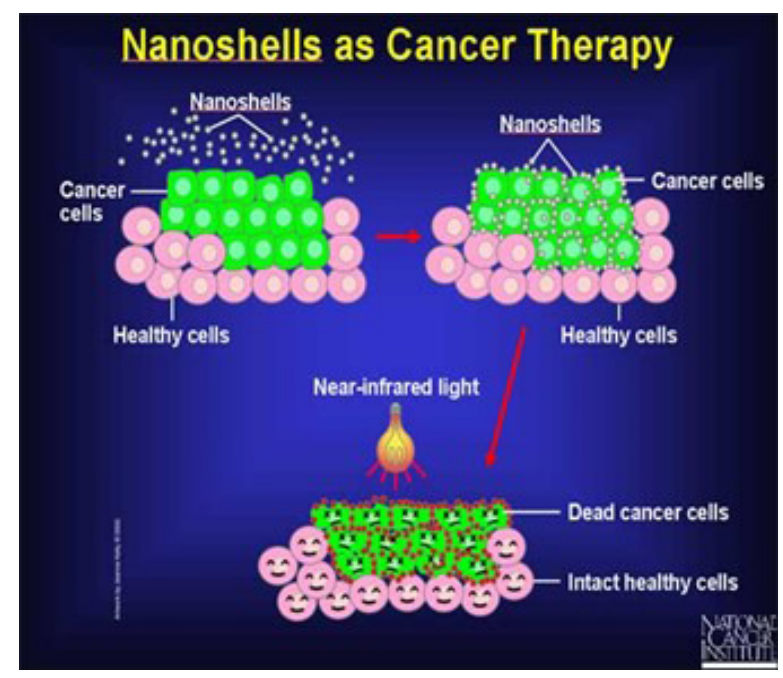

FIGURE 17. Use of nanoshells for cancer treatment (Source: National Cancer Institute).

Gold nanoshells exhibit unique optical properties because their interaction with the electromagnetic field is greatly intensified by a phenomenon known as localized surface plasmon resonance. They are designed to absorb radiation at various frequencies absorb certain types of radiation. Once the nanoshells are attached to the cancerous cells, only laser light is needed to treat cancer. Near-infrared (NIR) light passes through the body 
and reaches the gold nanoshell. The tuned gold nanoshell receives the NIR light and converts the light energy into heat, killing the cancer cells. ${ }^{107}$

- Nanotubes: Nanotubes, usually made in carbon (CNTs), consist of carbon atoms arranged in a series of condensed benzene rings rolled up into a tubular structure. ${ }^{111}$ Carbon nanotubes (CNTs) are cylindrical molecules that consist of rolled-up sheets of single-layer carbon atoms (graphene). They can be single-walled (SWCNT) with a diameter of less than 1 nanometer ( $\mathrm{nm}$ ) or multi-walled (MWCNT), consisting of several concentrically interlinked nanotubes, with diameters reaching more than $100 \mathrm{~nm}$. Their length can reach several micrometers or even millimeters (Figure 18). ${ }^{112}$

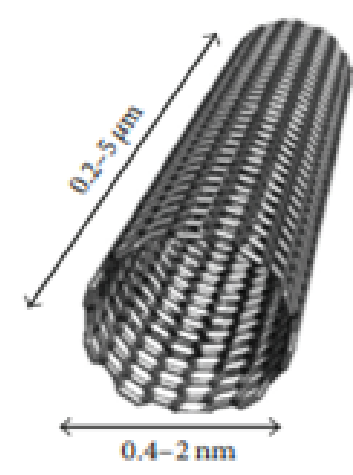

(a)

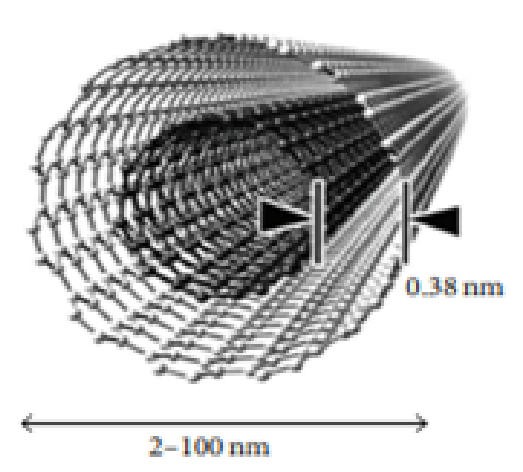

(b)
FIGURE 18. Conceptual diagrams of single-walled carbon nanotubes (a) and multiple-walled carbon nanotubes (b). ${ }^{111}$

Their impressive structural, mechanical, and electronic properties are due to their small size and mass, incredible mechanical strength, and high electrical and thermal conductivity. In medicine, nanotubes are used in pharmaceuticals, drug delivery systems, gene delivery and therapy, tissue engineering, bio-imaging, biosensor applications, lab-on-chip devices, photo-thermal therapy, diagnostics, and high-performance composites for implants. ${ }^{113,114}$

Although there are advantages of nanotubes (like biocompatibility, rigidity, mimicking of natural tissue nanofibers, stimulating the adhesion and proliferation of cells and ability to form strong 3-D architectures, high surface area, high photo-stability and absence of quenching, special optical, mechanical, and electronic properties) ${ }^{114}$ concerns related to their toxicity, biosafety, and biodegradation still remain. ${ }^{113}$ Examples of nanotechnology equipment in medicine include atom probes, atomic absorption spectrometer, profilometers, raman microscopes, calorimeters, cryogenic probe stations, scratch testers, flow chemistry reactors, graphene, surface analyzers, Spectroscopic ellipsometer, wafer bonders, $\mathrm{x}$-ray detectors, $\mathrm{x}$-ray diffractometer, etc. ${ }^{106}$

The challenges faced by nanotechnology include high manufacturing costs, technical challenges, raised skeptical opinions within the scientific community about the clinical relevance of nanomedicine. ${ }^{93}$ The competitive landscape of the industry has also been examined along with the profiles of the key players who include Abbott Laboratories, Arrowhead Pharmaceuticals Inc., General Electric Company, Luminex Corporation, Merck \& Co. Inc., Nanobiotix, Novartis AG, Pfizer Inc., Sanofi SA, Starpharma Holdings Limited. ${ }^{115}$

\section{Telemedicine and Telehealth}

The provision of primary healthcare has been challenging during the recent and current periods of COVID-19 due to overcrowding of medical services seekers to different health facilities. ${ }^{116}$ It is evident to many that COVID-19 accelerated the adoption of Telemedicine globally. ${ }^{117}$ Telemedicine uses electronic communications and information technologies to provide clinical services when participants are at different locations. ${ }^{118,119}$ Some writers prefer to use the term "telehealth" interchangeably with "telemedicine," but Telehealth is broader because it also considers even non-clinical services. Telehealth refers to 'the use of telecommunications and IT to provide access to health assessment, diagnosis, intervention, consultation, supervision and information across distance. ${ }^{120}$

Telemedicine is traced back many centuries, starting from ancient hieroglyphs and scrolls to share information about health-related events such as outbreaks or epidemics. This was followed by using smoke signals to warn nearby cities of sickness. ${ }^{120}$ In contemporary times, Telemedicine through telephone and video technology has been used since the 1960s in the military and space sectors. ${ }^{121}$ Apart from military services, Telehealth was first used in 1972 when Murphy and Bird conducted 500 
patient consultations via interactive television. ${ }^{122}$ Today, Telemedicine is applied in radiology, dermatology, surgical peer monitoring, medication management, mental health, diagnosis, patient monitoring, etc. ${ }^{123}$

The drivers of Telemedicine include: enhancement of care coordination, patients and doctors are fascinated by the services offered by Telemedicine, society, and healthcare tendency to digital life (in OECD countries, nearly $65 \%$ of people aged 65 to 84 years are estimated to have more than one chronic condition, a prevalence that reaches $89 \%$ for those aged 85 and over), bridging of the rural gap, continuous innovation in the consumer technology market, projected shortages in the health professional workforce, growth of consumerism in health care cost-effectiveness, quick access to medical services, ${ }^{123,124}$ improved quality, medication management, changes in care models. $^{125,126}$

The services offered by Telemedicine include specialist referral services (assisting a general practitioner in rendering a Diagnosis), direct patient care (sharing audio, video, and medical data between a patient and a health professional for use in generating a diagnosis, treatment plan, prescription or advice), remote patient monitoring (devices to remotely collect and send data to a monitoring station for interpretation), medical education and mentoring, consumer medical and health information, patient support service (reminders to take medication, supervision, scheduling of appointments and similar applications which are not implicitly medical). ${ }^{118}$

There are four key elements needed for a successful telemedicine program.

1. Collaboration tools are devices that help patients to connect with healthcare service providers. They include smartphones, laptops, tablets, etc. ${ }^{127}$

2. Medical peripherals are the diagnostic tools used in Telemedicine, such as otoscopes, ultrasound machines, or digital stethoscopes. ${ }^{127}$

3. Workflow represents adequate software to manage the complete process of connecting patients to medical professionals and to integrate Telemedicine with their existing IT resources. ${ }^{127}$
4. Cloud-based services: Cloud computing delivers different services through the Internet. These resources include tools and applications like data storage, servers, databases, networking, and software. When using cloud computing, the user is not required to be in a specific place to access it, allowing the user to work remotely. ${ }^{128}$ In Telemedicine, cloud-based services help user-friendly access to medical records for both clinicians and patients from anywhere they can access the Internet. ${ }^{129}$

When the world experienced COVID-19 pandemic, social distancing measures were put in place to fight its sustainability. Moreover, the rapid global spread of COVID-19 has increased the volume of data generated from various sources. ${ }^{130}$ The cloud technology had a major role in fighting the epidemic; it became a salvation for governments and organizations in numerous fields of life, education, health, industry, communication, remote surveillance, and more information (Figure 19). ${ }^{131}$

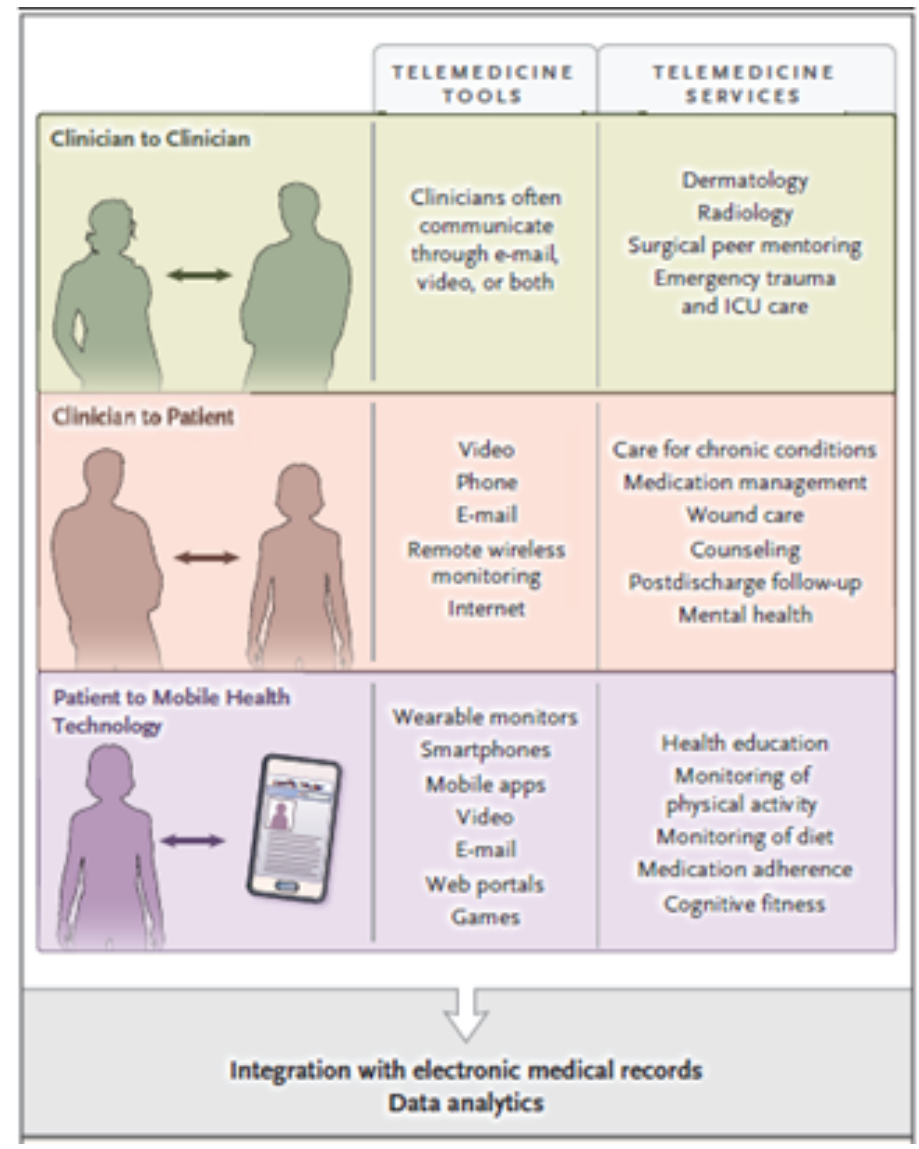

FIGURE 19. Use of Telemedicine by doctors and patient benefits. ${ }^{123}$ 
Generally, the lines of action of the telehealth program are based on three components, as presented in Figure 20.

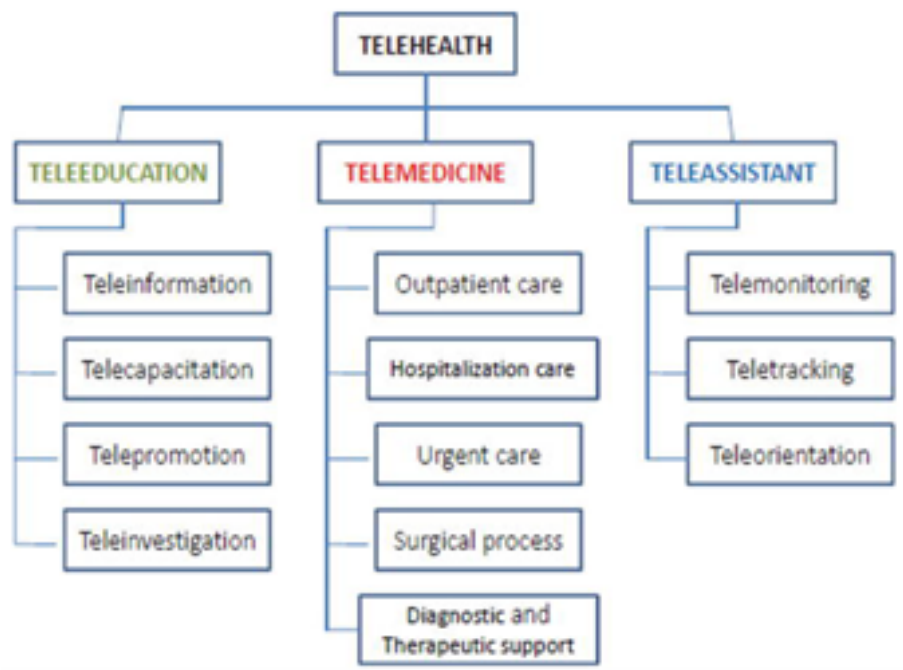

FIGURE 20. General lines of action of telehealth. ${ }^{132}$

From 2010 to 2017 the world experience growth in the use of Telemedicine, with three diseases dominating the growth rate. Those are diabetes, congestive heart failure (CHF), and chronic obstructive pulmonary disease (Figure 21).

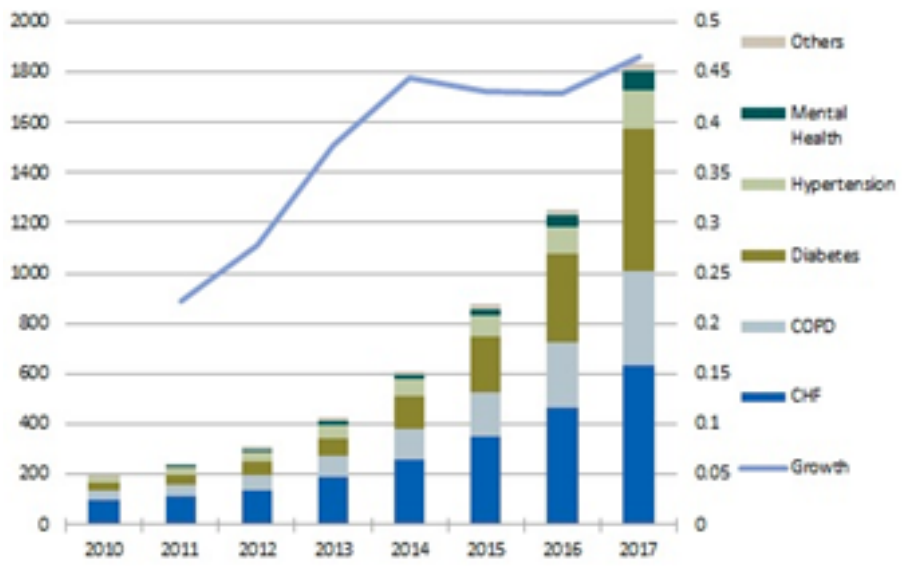

FIGURE 21. World Telehealth Patients (thousand) per disease. ${ }^{133}$

Since 2018, the quarterly investment in Telehealth has experienced peaks and bottoms, but when WHO officially declared COVID-19 as a pandemic on 13 March 2020, the investment in Telehealth has drastically increased compared to previous years, as presented in Figure 22.

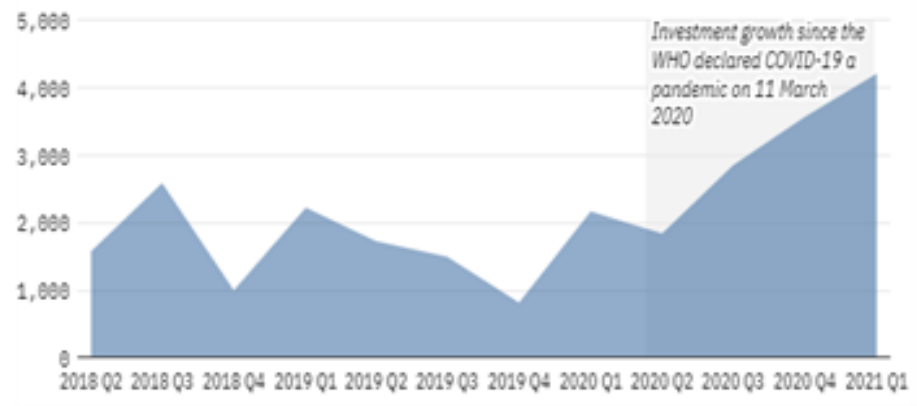

FIGURE 22. Quarterly global telehealth funding (2018-2021) in \$M. ${ }^{134}$

Generally, the global telemedicine market was valued at $\$ 50$ billion in 2019 , with forecast potential growth to increase to $\$ 460$ billion by $2030 .{ }^{135}$

There are three types of Telemedicine:

- Store and forward telemedicine or asynchronous Telemedicine. In this type of Telemedicine, patient information such as medical images or bio-signals can be sent to the specialist as needed when it has been acquired from the patient. ${ }^{136}$ It is regarded as the acquisition and storing of clinical information such as lab reports, data, images, sound, and videos that are then forwarded to (or retrieved by) another site for clinical evaluation. ${ }^{122}$

- Real-time video or synchronous Telemedicine. In this type of Telemedicine, consultations use video conferencing to connect the patient with the physician. Patients from their homes can use smartphones, tablets, or computers to interact with physicians. This method enables the physician to conduct a medical consultation as they would in person. ${ }^{122}$

- Remote monitoring telemedicine. This uses a range of technological devices to remotely monitor a patient's health and clinical signs. This is extensively used in the management of chronic diseases such as cardiovascular disease, diabetes mellitus, and asthma. ${ }^{136}$

The key challenges hindering the growth of Telemedicine are system development costs, digital literacy, Digital Technology Acceptance, less accurate diagnosis for specific images transmitted with Telemedicine concerning the original images, aspects linked to security and confidentiality in the doctor-patient relationship through 
appropriate interfaces, and system implementation by the involvement of different parties. ${ }^{132,137}$

Although Telemedicine has many challenges to overcome, there are also opportunities to sustain its development. They include gap service coverage (for example, in the USA, teleradiology predominates other services), urgent service coverage (a case of a mobile telemedicine system for consulting acute stroke even remotely by employing a wireless LAN or a mobile phone network), and videoenabled multisite group chart rounds (model of medical education liked to clinical care). ${ }^{138,139}$

\section{Big Data}

The healthcare landscape is saturated with a large, diversified amount of data. Big Data in healthcare is overwhelming because of its volume and the diversity of data types, and the speed at which it must be managed. ${ }^{140}$ Those data could be an enabling resource for deriving insights for improving care delivery and reducing waste. ${ }^{141}$ Over more than a decade, as in other industries, the medical industry has experienced rapid digitization due to an increase in electronic medical records (EMR). ${ }^{142}$

Driven by mandatory requirements and the potential to improve the quality of healthcare delivery and obtain the best healthcare services meanwhile reducing the costs, requires a significant diversified quantity of electronic health records to help in clinical decision support, disease surveillance, and population health management. ${ }^{140,143}$

Big Data should be collected and used to ensure agreements between patients, healthcare service providers, and policy and research. Today, there is no common definition to explain what Big Data is. However, some researchers tried to formulate the meaning of Big Data. According to McKinsey the term "Big Data" refers to "datasets whose size is beyond the ability of typical database software tools to capture, store, manage, and analyze."144 Big data is unmanageable using traditional software. We need technically advanced applications and software to employ fast and cost-efficient high-end computational power to utilize it properly. The term Big Data is described by the following characteristics: value, volume, velocity, variety, veracity, and variability, denoted as the 6 "Vs". ${ }^{143}$
According to some studies have shown that $93 \%$ of healthcare organizations have experienced a data breach because personal data is extremely valuable and profitable on the black markets, and this pushed organizations to start using data analytics to help them prevent security threats by identifying changes in network traffic, or any other behavior that reflects a cyber-attack. ${ }^{146}$

Big Data help to identify individual and community trends and develop better treatment plans or predict at-risk patients, forecast patient admissions trends and schedule the correct number of staff, drive innovation, compare chronic disease and population growth in neighborhoods, streamline insurance claims processes, easy detection of fraud and inventory tracking. ${ }^{147}$ The global health data in 2013 only was estimated to be 153 Exabytes, with forecast potential growth to 2,314 Exabytes in 2020 alone. $^{135}$

Big Data analytics are divided into four categories:

- Descriptive analytics. This consists in decrying the current situation and reporting on it.

- Diagnostic analytics aim to explain why certain events occurred and what factors triggered them.

- Predictive analytics. This reflects the ability to predict future events; it also helps identify trends and determine probabilities of uncertain outcomes.

- Prescriptive analytics. This proposes suitable actions leading to optimal decision-making.148

The global Big Data analytics in healthcare market size was valued at $\$ 16.87$ billion in 2017 and is projected to reach $\$ 67 .{ }^{82}$ billion by 2025 , growing at a CAGR of $19.1 \%$ from 2018 to $2025 .{ }^{149}$

The nine stages that make analyzed data useful are shown in Figure 23. Big Data come from clinical practices and research, patient-generated data, medical claims, electronic healthcare records, social media, patient summaries, genomic and pharmaceutical data, clinical trials, Telemedicine, mobile apps, sensors, and information on wellbeing, behavior, and socio-economic indicators. ${ }^{142,144}$ Big Data are used in medical services to gain advantages as shown in Figure 24, and Big Data architecture for healthcare is presented in Figure 25. 


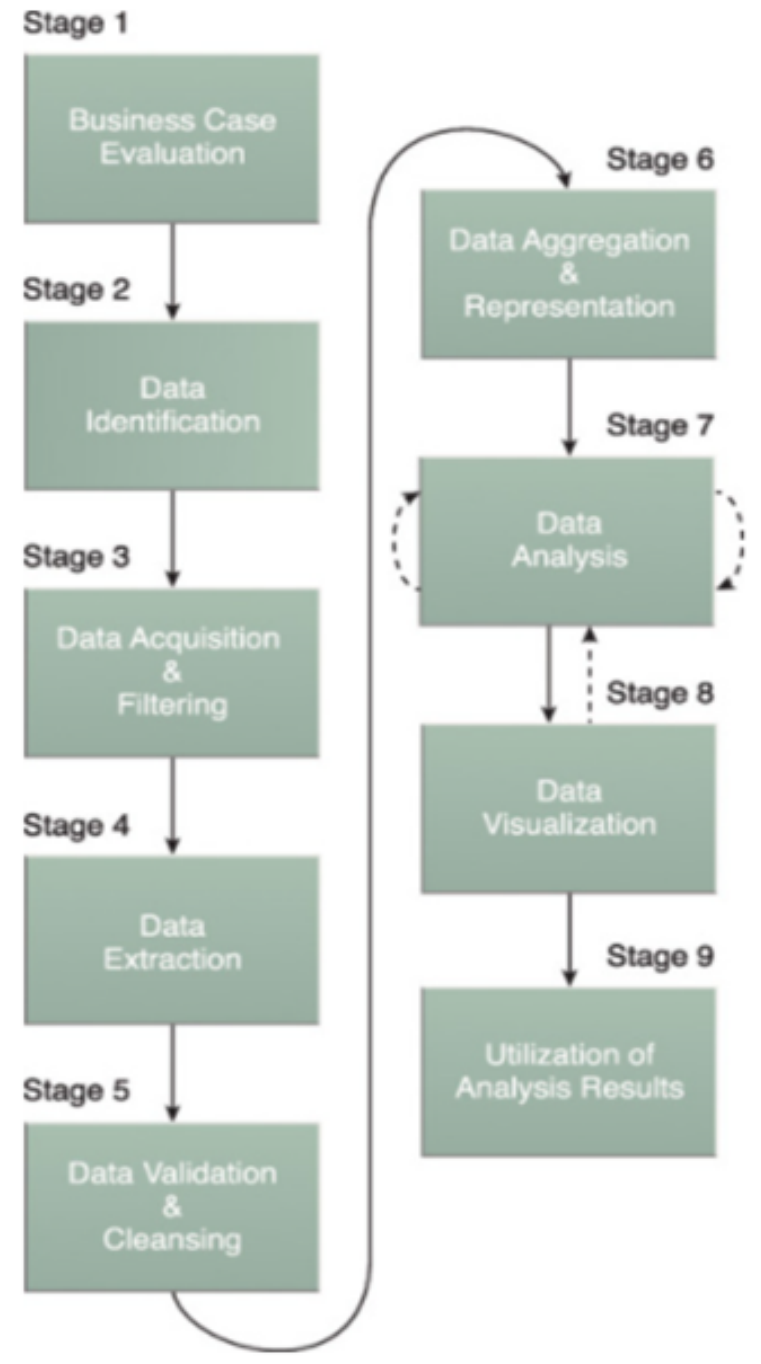

FIGURE 23. The nine stages of the Big Data analytics lifecycle. ${ }^{150}$

The Big Data analysis ensures that the health facility manager sees a big picture of the hospital, the attendance, its nature, the costs incurred, etc., which will help run it smoothly. An example of a dynamic dashboard for patient care is shown in Figure 26. ${ }^{146}$ The challenges facing Big Data technology are: segmentation of data in healthcare providers (clinical data, financial data, administrative data, patient data are not linked and shared), protection of patient's privacy, ${ }^{151}$ data capturing, cleaning and storage, stewarding and querying. ${ }^{152,153}$

There are several challenges in adopting Big Data technology: data in many health care providers are often segmented or siloed, complicated use Big Data is complicated, long system response time. ${ }^{151,154}$ The key players

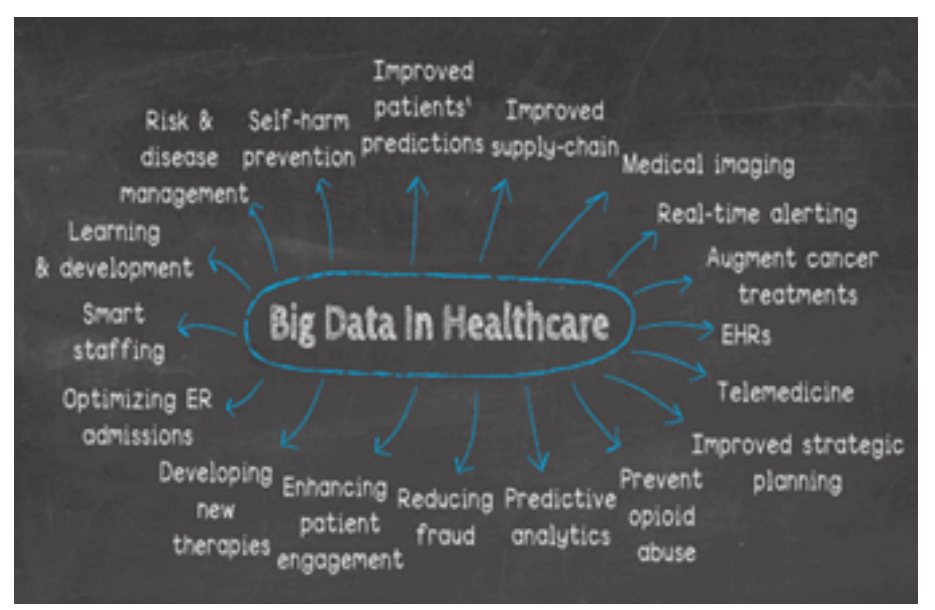

FIGURE 24. Application areas of Big Data technology in medicine. ${ }^{146}$

in healthcare data analytics include IBM, Cerner, Health catalyst, McKesson, Oracle. ${ }^{155}$

\section{CONCLUSION}

In conclusion, driven by needed increases in medical productivity, the growing prevalence of chronicling diseases, the increasing aging population, and the increasing emphasis by healthcare agencies towards early diagnosis and treatment, many countries and healthcare providers are struggling to scale-up technology level to provide adequate services to patients. In addition, physicians themselves believe in introducing new technologies to help them prevent, diagnose, treat, monitor, and care for patients.

Technology advancement has proven effective in providing access to information, facilitating remote care, improving efficiency by connecting the patients with physicians, cost-effective and time-saving solutions. Medical technologies encompass data centers, medical devices, software, drugs, IT services, public clouds, cybersecurity, communication services, surgical procedures, and Internet of things.

The medical technology market is growing fast in Asia, with different and bulky products available on almost all global markets. As a result, the global market for medical devices only is projected to grow from USD 455.34 billion in 2021 to USD 657.98 billion in 2028 .

The key challenges humping the development of medical technology are biomedical complexity, standardization, 


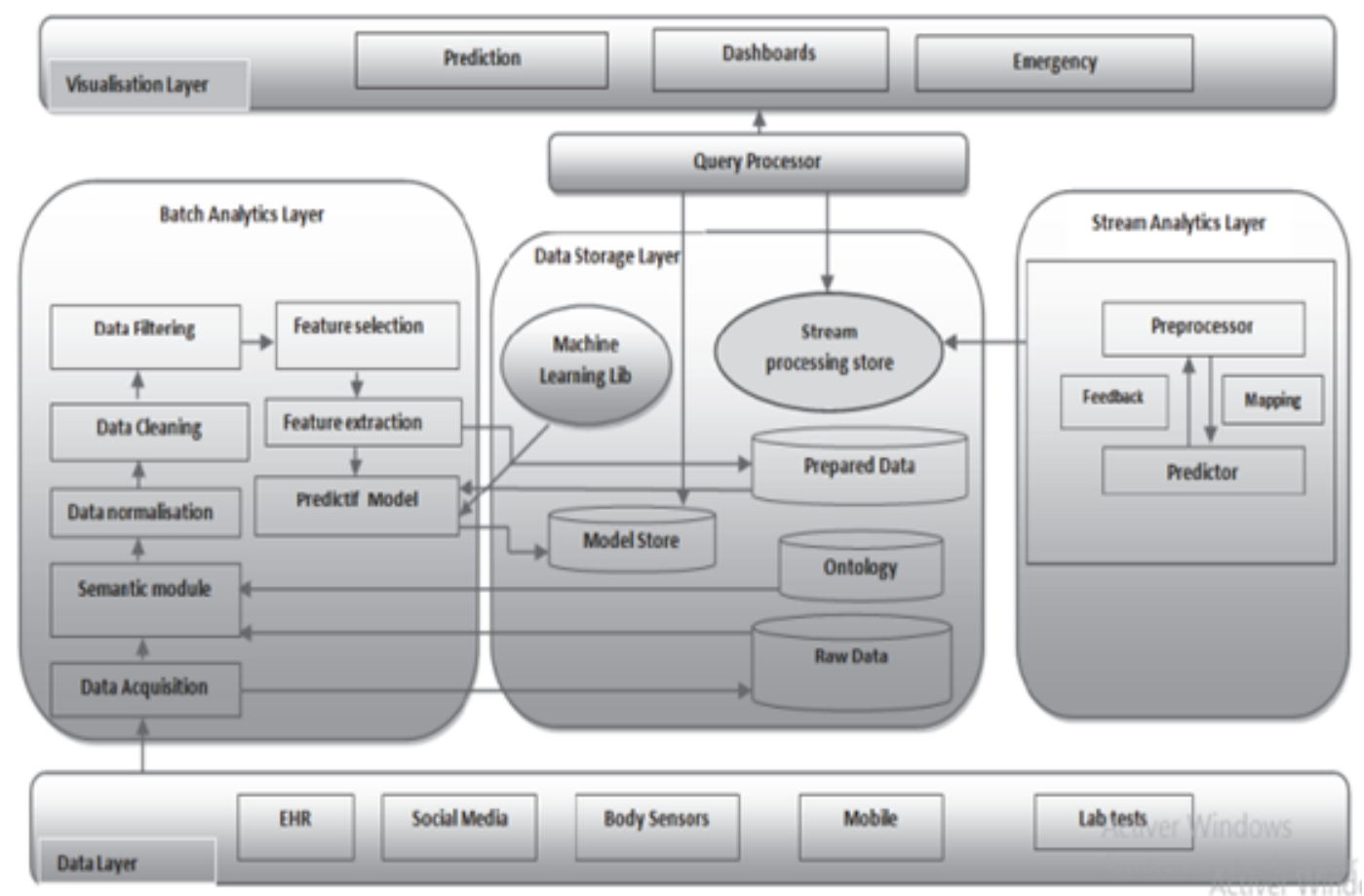

FIGURE 25. Big Data architecture for health system. ${ }^{148}$

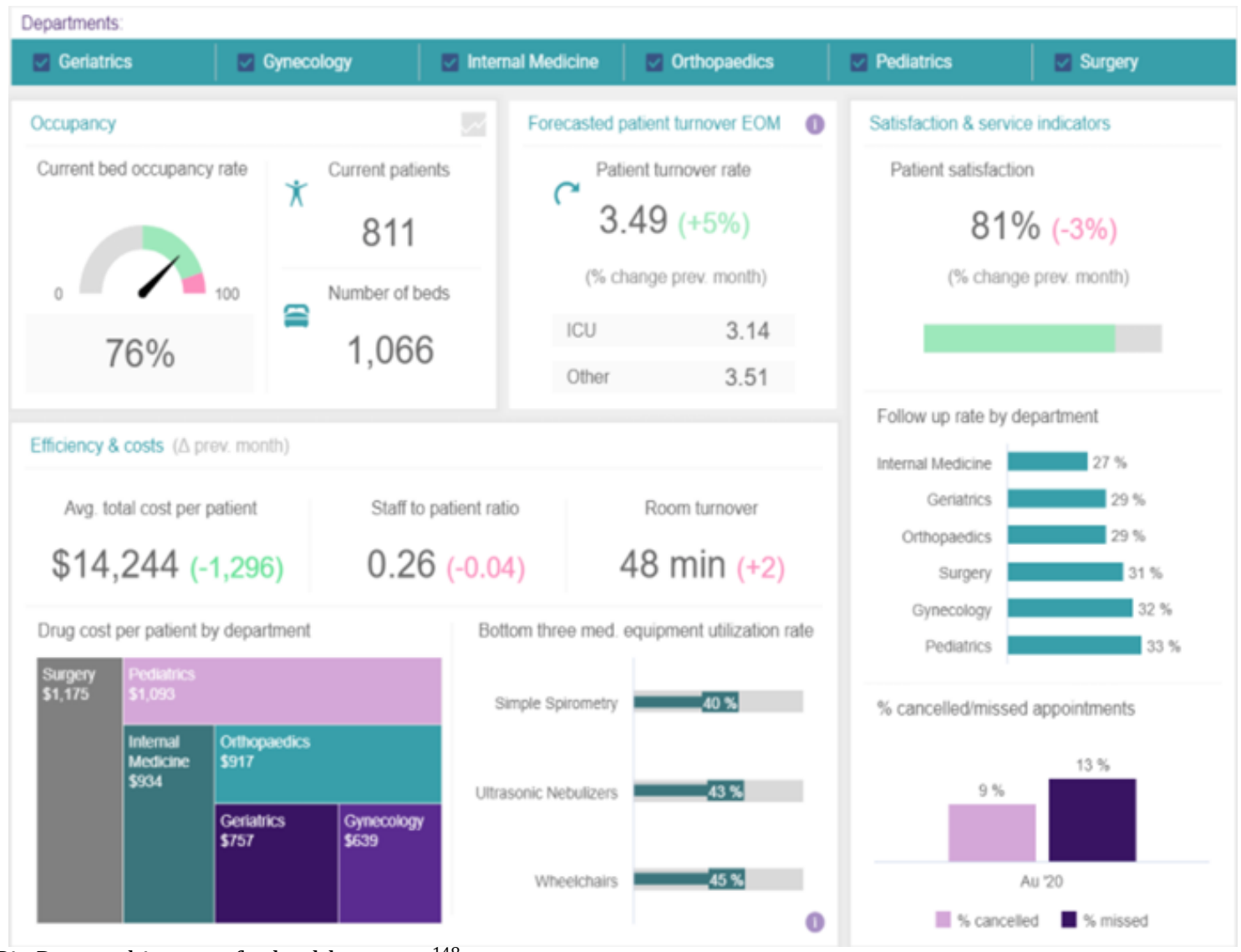

FIGURE 25. Big Data architecture for health system. ${ }^{148}$ 
cybersecurity and data privacy, higher starting costs, and regulatory and environmental consideration.

The revolution of healthcare technology applications in medical services requires knowledge and skills in assessment, planning, procurement, inventory management, installation, and maintenance. Therefore, healthcare providers need to be watchful about Healthcare Technology Assessment (HTA) to ensure evidence about safety, effectiveness, relevance, technology outcomes, and alternative technologies when running a particular technology. HTA is a multidisciplinary process that summarizes information about the medical, social, economic, and ethical issues related to using health technology systematically, transparent, unbiased, and robustly.

According to World Health Organization, only 70 countries worldwide have a National Agency or committee that provides HTA reports to the Ministry of Health, among which only 3 countries come from Africa (Benin, Mali and South Africa). Governments are therefore encouraged to adopt HTA programs because they provide information to support decisions about priorities in healthcare. Furthermore, HTA involves different parties, including patients' experience, caregivers, policymakers, physicians, HTA agencies, clinical engineering industry representatives, payers, pharma groups, and finance managers.

\section{REFERENCES}

1. F. M. T. Badi H.Baltagi, "Medical Technology and the production and healthcare," Iza, Bonn, 2011.

2. M. C. D. David E.Wamble, "The Effect of Medical Technology Innovations on Patient Outcomes,19902015:Results of a Physician Survey," Journal of Managed Care \&specialty Pharmacy, vol. 25, no. 1, p. 1, 2019.

3. L. M. Aggarwal, "Advances in Medical Technology and its Impact on Healthcare in Developing Countries,"International Journal of Radiology\&Radiation Therapy, vol. 2, no. 2, p. 2, 2017.

4. J. Lu, "Will Medical Technology Deskill Doctors?," International Edication Studies, vol. 9, no. 7, p. 1, 2016.

5. A. D. Keyzer, "The Belgian Medicla Technology Facts\&Figures," BeMedtech, 2018.
6. O. L. M. Giovanni Briganti, "Artificial intelligence in medecine:Today and tomorrow," Frontiers in medecine, vol. 7, no. 27, pp. 1-6, 2020.

7. C. S.Goodman, "Introduction to Health Technology assessment," The Lewin Group, 2014.

8. C. S. e. al, "Medical technology as a key driver of rising health expenditure: disentangling the relationship," ClinicoEconomics and Outcomes Research, p. 1, 2013.

9. A. J. Haj, "The grand Challenges of Medical Technology," Frontiers in medical technology, vol. 2, no. 1, p. 1, 2020.

10. S. K. T. S. T. F. Masataka Hasegawa, "Formal Implementation of Cost-Effectiveness Evaluations in Japan:A Unique Health Technology Assessment System," Elsevier, pp. 1-12, 2019.

11. D. U. P. Y. Dirk Freiland, "Market Study Medical Technology," Clairfield International, 2020.

12. I. T. H. e. al, "The use of advanced medical technologies at home:a systematic review of the literature," BMC Public Health, p. 1, 20 '8.

13. C. Stewart, "Total global medical technology revenue from 2011 to 2024," statista.com, 22 September 2020. [Online].Available:https://www.statista.com/statistics/325809/worldwide-medical-technology-revenue/. [Accessed 28 January 2022].

14. D. Y. M. e. al, "Wearable Technology Acceptance in Health Care Based on National Culture Differences: Cross-Country Analysis Between Chinese and Swiss Consumers," JOURNAL OF MEDICAL INTERNET RESEARCH, vol. 22, no. 10, p. 2, 2020.

15. H. L. L. Yiwen Gao, "An empirical study of wearable technology acceptance in healthcare," Industrial Management \& Data Systems, vol. 115, no. 9, pp. 1-22, 2015.

16. E. M. e. al., "Factors to Consider in the Use of Vital Sign Wearable to minimize Contact With Stable COVID-19 Patients:Experience of its Implementation during the pandemic," Frontiers in Digital Health, vol. 3, 2021.

17. J.-M. BUCHILLY, "Emerging Trends in Wearable Technology Across Several Markets," Fischer Connectors, Saint-Prex, 2017. 
18. S. D. A. W. A. Mostafa Haghi, "Wearable Devices in Health Monitoring from the Environmental towards Multiple Domains: A Survey," Sensors, p. 1, 2021.

19. A. K. Y. e. al, "Wearables in Medicine," Advanced Materials, p. 1, 2018.

20. A. O. e. al, "A Survey on Wearable Technology: History, State-of-the-Art and Current Challenges," Elservier, pp. 1-37, 2021.

21. Sean, "China shipped over 35 million wearable devices in Q3 2021, hearable sales rose 40\% YoY: IDC," GIZMOCHINA, 9 December 2021. [Online]. Available: https://www.gizmochina.com/2021/12/09/chinaship-35mn-wearable-device-in-q3-2021/. [Accessed 19 January 2022].

22. D. Slotta, "Market share of wearable devices in China 2017-2021, by manufacturer," Statista.com, 22 November 2021. [Online]. Available: https://www. statista.com/statistics/984200/china-market-shareof-wearable-electronics-by-manufacturer/. [Accessed 19 January 2022].

23. A. B. R. Raymond Collier, "Wearable Technologies for Healthcare Innovations," in SAIS2015 PROCEEDNGS, 2015.

24. H. Baum, "Mobile devices, apps and wearables for healthcare," 2017.

25. A. C. e. al, "The Rise of Wearable Devices during the COVID-19 Pandemic: A Systematic Review," Sensors, pp. 1-22, 2021.

26. A. O. Hatice Ceylan Koydemir, "Wearable and Implantable Sensors for Biomedical Applications," Annual Review of Analytical Chemistry, pp. 1-20, 2018.

27. H. C. A. e. al, "Wearable devices for the detection of COVID-19," biosensors, vol. 4, pp. 1-2, 2021.

28. A. Y. Cemre Eda Erkılıç, "Evaluation of the wearable technology market within the scope of digital health technologies," Gazi Journal of Economics\&Business, vol. 6, no. 3, p. 2, 2020.

29. A. S. e. al, "Wearables and the internet of things: considerations for the life and health insurance industry," British Actuarial Journal, vol. 24, pp. 1-31, 2018.
30. S. E. S. A. G. Vivek Kaul, "History of artificial intelligence in medicine," GASTROINTESTINAL ENDOSCOPY, vol. 92, no. 4, pp. 1-6, 2020.

31. M. Voltolina, "Supporting AI Deployment with a Toolkit for Implementers," hospitalnews.com, 29 October 2021. [Online]. Available: https://hospitalnews. com/supporting-ai-deployment-with-a-toolkit-forimplementers/. [Accessed 30 December 2021].

32. J. E. M. A. Christian HARTMANN, "Trends and Developments in Artificial Intelligence," European Commision, Challenges to the Intellectual Property Rights Framework.

33. P. M. P. V. K. R. Amisha, "Overview of artificial intelligence in medicine," Journal of Family Medecine and Primary Care, pp. 1-4, 2019.

34. H. A. G. P. Almir Badnjević, "ARTIFICIAL INTELLIGENCE IN MEDICAL DEVICES: PAST, PRESENT AND FUTURE," Science, Art \& Religion, vol. 1, 2021.

35. M. D. Mei Chen, "Artificial intelligence in healthcare:An essential guide for health leaders," Healthcare Management Forum, vol. 33, no. 1, pp. 1-9, 2020.

36. F. O. Monique Mrazek, "Artificial Intelligence and Healthcare in Emerging Markets," EMCompass, September, 2020.

37. M. G. Bertalan Meskó, "A short guide for medical professionals in the era of artificial intelligence," Digital medecine, vol. 3, pp. 1-8, 2020.

38. P. Vadapalli, "Top 7 Challenges in Artificial Intelligence in 2022," upGrad, 8 January 2021. [Online]. Available:https://www.upgrad.com/blog/topchallenges-in-artificial-intelligence/. [Accessed 19 January 2022].

39. G. Todorov, "65 Artificial Intelligence Statistics for 2021 and Beyond," Semrush, 2021 February 2021. [Online].Available:https://www.semrush.com/blog/ artificial-intelligence-stats/. [Accessed 20 December 2021].

40. N. Savage, "The race to the top among the world's leaders in artificial intelligence," Nature Index, 9 December2020.[Online].Available:https://www.nature.com/articles/d41586-020-03409-8. [Accessed 20 December 2021]. 
41. D. H. e. al, "Artificial Intelligence: Power for Civilisationand for Better Healthcare," Public Health Genomics, vol. 22, no. 145, pp. 1-17, 2019.

42. A. M. V. Jeff Mason, "An Overview of Clinical Applications of Artificial Intelligence," CADTH, Ottawa, 2018.

43. P. S. A. Trishan Panch, "Artificial intelligence, machine learning and health systems," Journal of Global Health, vol. 8, no. 2, pp. 1-8, 2018.

44. B.Yegnanarayana, Artificial Neural Networks, Delhi: Printice-Hal of India, 2006.

45. E. Burns, "What is a neural network? Explanation and examples," Techtarget, 05 Aprl 2021. [Online]. Available:https://www.techtarget.com/searchenterpriseai/definition/neural-network. [Accessed 20 December 2021].

46. I. C. Education, "Neural Networks," IBM, 17 August 2020. [Online]. Available: https://www.ibm.com/ cloud/learn/neural-networks. [Accessed 20 December 2021].

47. Y. B. Manel Zribi, "Neural networks in the medical decision making," International Journal of Computer Science and Informatics, vol. 14, no. 2, p. 2, 2016.

48. M. G. d. M. Alexandre Baratella Lugli, "Computer vision and Artificial Intelligence Techniques Applied to Robot Soccer," International Jouirnal of Innovative Computing,Information and Control, vol. 13, no. 3, pp. 1-4, 2017.

49. A. Abdoullaev, "Artificial Intelligence in the Pandemic Era: Benefits \& Challenges," BBNTimes, 7 September 2021. [Online]. Available: https://www.bbntimes. com/technology/what-are-the-biggest-challengesin-artificial-intelligence-and-how-to-solve-them. [Accessed 19 January 2022].

50. T. Novicio, "10 Best AI Stocks for 2022," Yahoo, 8 January 2022. [Online]. Available: https://finance. yahoo.com/news/10-best-ai-stocks-2022211304622. html?guccounter=1\&guce_referrer=aHR0cHM6L y93d3cuZ29vZ2xlLmNvbS8\&guce_referrer_sig=A QAAAEnF48r8SKRjfGlOEDgRnKPkNifCe6qBoP90 XMz3utgufOed2LTPLE_u4A195iIhGLWMn7qXYrsoKlmKXJC8v73r0NbRNPiCnks2-Hd. [Accessed 19 January 2022].
51. C. GRAY, "Top 10 Artificial Intelligence Brands," AIMagazine, 2021 October 2021. [Online]. Available: https://aimagazine.com/ai-applications/ top-10-artificial-intelligence-brands. [Accessed 19 January 2022].

52. M. Attaran, "Blockchain technology in healthcare: Challenges and opportunities," International Journal of Healthcare Management, pp. 1-15, 2020.

53. Y. J. Mian Zhang, "Blockchain for healthcare records:a data perspective," Chicago, 2018.

54. M. Intelligence, "BLOCKCHAIN MARKET IN HEALTHCARE - GROWTH, TRENDS, COVID-19 IMPACT, AND FORECASTS (2022 - 2027)," Mordor Intelligence, 12 August 2021. [Online]. Available: https://www. mordorintelligence.com/industry-reports/blockchainmarket-in-healthcare. [Accessed 25 January 2022].

55. 0. 0. B. E. M. Anuraag A. Vazirani, "Blockchain vehicles for efficient Medical Record management," Ditial Medecine, vol. 3, no. 1, pp. 1-5, 2020.

56. T. Wilson, "British hospitals use blockchain to track COVID-19 vaccines," Reuters, 19 January 2021. [Online]. Available: https://www.reuters.com/article/ uk-health-coronavirus-blockchain-idUSKBN2900RW. [Accessed 25 January 2022].

57. N. India, "Global Blockchain Technology in Healthcare Market Gaining Momentum-Projected to Reach USD 4,720.96 Million by 2027," BlueWeave Consulting, 18 March 2021. [Online]. Available: https://www.globenewswire.com/news-release/2021/03/18/2195742/0/ en/GlobalBlockchain-Technology-in-HealthcareMarket-Gaining-Momentum-Projected-to-ReachUSD-4-720-96-Million-by-2027.html. [Accessed 25 January 2022].

58. K. G. E. S. M. M. Matthew N. O. Sadiku, "Block chain Technology in Healthcare," International Journal of Advances in Scientific Research and Engineering (ijasre), vol. 4, no. 5, pp. 1-7, 2018.

59. M. M. R. C. Kurt Yaeger, "Emerging Blockchain Technology Solutions for Modern Healthcare Infrastructure," Journal of Scientific Innovation in medecine, vol. 2, no. 1, pp. 1-7, 2019. 
60. A. A. S. e. al, "Applications of Blockchain Technology in Medicine and Healthcare:Challenges and Future Perspectives," Cryptography, vol. 3, no. 3, pp. 1-16, 2019.

61. V. Kaushik, "Blockchain Technology Explained-Components and Applications," analyticssteps.com, 17 September 2021. [Online]. Available: https://www. analyticssteps.com/blogs/blockchain-technologyexplained-components-and-applications. [Accessed 22 December 2021].

62. H.-E. K. O.-M. Tsung-Ting Kuo, "Blockchain distributed ledger technologies for biomedical and health care applications," Journal of the American Medical Informatics Association, vol. 24, no. 6, pp. 1-10, 2017.

63. A. H. e. al, "Blockchain technology applications in healthcare: An overview," International Journal of Intelligent Networks, vol. 2, pp. 1-10, 2021.

64. A. A. G. M. Ahmed Farouk, "Blockchain Platform for Industrial Healthcare: Vision and Future Opportunities," Toronto, 2020.

65. T. K. M. e. al, "'Fit-for-purpose?' - challenges and opportunities for applications of blockchain technology in the future of healthcare," BMC Medecine, pp. 1-17, 2019.

66. H. Mittal, "Blockchain technology: architecture, consensus protocol and applications," in Blockchain3.0 for sustainable development, Boston, 2021, pp. 1-8.

67. E. W. Kathleen E. Wegrzyn, "Types of Blockchain: Public, Private, or Something in Between," FOLEY\&LARDNER LLP, 2021 August 2021. [Online]. Available: https:// www.foley.com/en/insights/publications/2021/08/ types-of-blockchain-public-private-between. [Accessed 25 January 2022].

68. E. C.-H. K. Lei Hang, "A Novel EMR Integrity Management Based on a Medical Blockchain Platform in Hospital," electronics, vol. 8, no. 467, pp. 1-30, 2019.

69. K. B. Mariana Fernandez, "Role of Blockchain in Precision Medicine:Challenges, Opportunities, and Solutions," Frost and Sullivan, Texas, 2015.

70. M. B. Hoy, "An introduction to the blockchain and its implication for libraries and Medecine," med Ref Serv Q 2017.
71. Y. M. K. Z. Tirth Ginoya, "A Historical Review of Medical Robotic Platforms," Journal of Robotics, vol. 2021, pp. 1-13, 2021.

72. A. O. e. al, "Medical and Healthcare Robotics," IEEE Robotics \&Automation magazine, Stanford, 2014.

73. S. P. K. C. B. B. Shripad Shashikant Chopade, "Robotics in Medicine Applications," Interanational Journal of Engineering Research and Applications, vol. 3, no. 5, pp. 1-5, 2013.

74. S. A. e. al, "Medical telerobotic systems: current status and future trends," BioMedical Engineering Online, pp. 1-44, 2016.

75. D. B. Mesko, "Medical robots: Nine exciting facts," Hospitalnews.com, 12 May 2019. [Online]. Available: https://hospitalnews.com/medical-robots-nineexciting-facts/. [Accessed 30 December 2021].

76. L. D. Riek, "Healthcare Robotics," California University, San Diego, 2017.

77. Tammy Tran, "Medical Robotics: A profit Machine," Sickenomics.com, June 2021. [Online]. Available: https://www.sickeconomics.com/2021/07/02/ medical-robotics-stocks/. [Accessed 30 December 2021].

78. K. Mackay, "Investing in Medical Robotics," VTM, 22 November 2021. [Online]. Available: https://www. valuethemarkets.com/analysis/investing-in-medicalrobotics. [Accessed 30 December 2021].

79. R. C. A. M. Zrinjka DOLIC, "Robots in healthcare:a solution or a problem?," Luxemberg, 2019.

80. Frost\&Sullivan, "Robotics in Healthcare," Business FInland, 2020.

81. D. PARTIDA, "What Are the Main Components of Robots?," Rehack.com, 7 December 2020. [Online]. Available: https://rehack.com/trending/science/ what-are-the-main-components-of-robots/. [Accessed 11 January 2022].

82. D. B. M. Research, "Global Medical Robots Market - Industry Trends and Forecast to 2028," Globe Newswire, Sydney, 2021. 
83. M. J. e. al, "Robotics Applications in COVID-19: A Review," Journal of Industrial Integration and Management, vol. 5, no. 4, pp. 1-30, 2021.

84. WHO, "Robots use in Rwanda to fight against COVID-19," World Health Organisation, 31 July 2020. [Online]. Available: https://www.afro.who.int/news/ robots-use-rwanda-fight-against-covid-19. [Accessed 11 January 2022].

85. E. ASHIMWE, "Rwanda deploys more robots in Covid-19 fight," Newtimes, 0902 2021. [Online]. Available:https://www.newtimes.co.rw/news/ rwanda-deploys-more-robots-covid-19-fight. [Accessed 1101 2022].

86. M. C. e. al, "Use of Technologies in COVID-19 Containment in Rwa," Rwanda Public Health Bulletin, vol. 2, no. 2, pp. 1-6, 2020.

87. H. Shin, "Armed with disinfectant and admonishments, South Korean robot fights coronavirus spread," Reuters, 1 June 2020. [Online]. Available: https:// www.reuters.com/article/us-health-coronavirussouthkorea-robots-idUSKBN23816M. [Accessed 2022 January 2022].

88. T. Hornyak, "What America can learn from China's use of robots and telemedicine to combat the coronavirus," CNBC, 18 March 2020. [Online]. Available: https:// www.cnbc.com/2020/03/18/how-china-is-usingrobots-and-telemedicine-to-combat-the-coronavirus. html. [Accessed 11 January 2022].

89. B. L. Patrick Boisseau, "Nanomedicine, Nanotechnology in medicine," HAL, Grenoble, 2011.

90. H. B. e. al, "Nanomedicine: Application Areas and Development Prospects," Internatioal Journal of Molecular Sciences, vol. 12, pp. 1-19, 2011.

91. K. Jain, "Nanomedicine: Application of Nanobiotechnology in Medical Practice," Medical Principles and Practice, vol. 18, pp. 1-13, 2008.

92. J. Li Tang, "Nonporous silicananoparticlesfornanomedicine application," Elsevier, vol. 8, no. 290-312, pp. 1-23, 2013.

93. L. S. e. al, "Thirty Years of Cancer Nanomedicine:Success, Frustration, and Hope," cancers, vol. 11, pp. 1-21, 2019.
94. K. M. e. al, "History and Possible Uses of Nanomedicine Based on Nanoparticles and Nanotechnological Progress," Journal of Nanomedicine\&Nanotechnology, vol. 6, no. 6, pp. 1-7, 2015.

95. B. Y. K. e. al, "Current Concept: Nanomedecine," The new England Journal of Medicine, vol. 363, pp. 1-10, 2010.

96. Y. G. e. al., Nanomedicine, Ontario: Springer, 2014.

97. S. S. S. S. Rajiv Saini, "Nanotechnology: The Future Medicine," Journal of Cutaneous and Aesthetic Surgery, vol. 3, no. 1, pp. 1-12, 2010.

98. MarketWatch, "The Nanomedicine Market report (2021-2027) covers segment data, including: type segment, industry segment, channel segment etc. cover different segment Nanomedicine Market size, both volume and value. Also cover different industries client's information,", Marketwatch.com, 24 December 2021. [Online]. Available: https://www.marketwatch.com/ press-release/nanomedicine-market-size-2022-globalindustry-updates-leading-playersfuture-growthbusiness-prospects-forthcoming-developments-andfuture-investments-by-forecast-to-2027-2021-12-24. [Accessed 28 January 2022].

99. M. A. Muhammad Zia-ur-Rehman, "Recent Progress of Nanotoxicology in Plants," in Nanomaterials in Plants, Algae, and Microorganisms, Amsterdam, Alsevier, 2018.

100. M. P. Dr. Tomislav Meštrović, "Quantum Dots in Biology and Medicine," Newsmedical,net, 23 August 2018. [Online]. Available: https://www.news-medical.net/ life-sciences/Quantum-Dots-in-Biology-and-Medicine. aspx. [Accessed 17 January 2022].

101. A. M. W. e. al., "Quantum dots in biomedical applications," Acta Biomater, pp. 44-63, 2019.

102. N. B. e. al, "Pharmaceutical and biomedical applications of," International Journal of Artificial Cells, Nanomedicine, and Biotechnology, pp. 1-12, 2015.

103. P. C. e. al, "Nanoparticles: structure, properties, preparation and behaviour in environmental media," Researchagate.net, pp. 1-19, 2008. 
104. F. L. O. e. al, "Algal Nanoparticles: Synthesis and Biotechnological potentials," INTECH, Rang-Du-Fliers, 2016.

105. P. S. Samir Mitragotri, " Organic nanoparticles for drug delivery and imaging," University of California, Washington, 2014.

106. B. Cuffari, "Organic vs. Inorganic Nanomaterials for Drug Delivery Applications," AzoNano, 29 October 2021. [Online]. Available: https://www.azonano. com/article.aspx?ArticleID=5855. [Accessed 26 January 2022].

107. I. V. S. T. Shanbhag PP, "Gold nanoshells: A ray of hope in cancer diagnosis and treatment," Nuclear Medicine and Biomedical Imaging, vol. 2, no. 1, pp. 1-5, 2017.

108. K. S. e. al, "Nanoshell particles:synthesis,properties and applications," Current Science Association, vol. 91, no. 8, pp. 1-15, 2006.

109. A. M. Mohamadreza Baghaban-Eslaminejad, "The role of nanomedicine, nanotechnology, and nanostructures on oral bone healing, modeling, and remodeling," in Nanoshell, Sciencedirect, 2017.

110. S. A. Amirhossein Ahmadi, "Potential applications of nanoshells in biomedical sciences," Journal of Drugs Targeting, pp. 1-15, 2013.

111. H. H. e. al, "Carbon Nanotubes: Applications in Pharmacy and Medicine," BioMed Research International, pp. 1-13, 2013.

112. S. P. e. al, "Applications of carbon nanotubes-based biomaterials in biomedical nanotechnology," Nanosci Nanotechnol, vol. 6, no. 7, pp. 1883-1904(22), 2006.

113. B. R. C. d. M. e. al, "Recent advances in the use of carbon nanotubes as smart biomaterials," J. Mater. Chem. B, vol. 7, no. 9, pp. 1343-1360, 2019.

114. H. Z. e. al, "Carbon Nanotubes: Smart Drug/Gene Delivery Carriers," International Journal of Nanomedicine, vol. 16, pp. 1-26, 2021.

115. RESEARCHANDMARKET, "Nanomedicine Market (20212026): Global Key Competitors Include Abbott Laboratories, Luminex Corporation, Merck \& Co, Nanobiotix and Novartis," RESEARCHANDMARKET, 29 December 2021. [Online]. Available: https://www.globenewswire. com/en/newsrelease/2021/12/29/2358689/28124/
en/Nanomedicine-Market-2021-2026-Global-KeyCompetitors-Include-Abbott-Laboratories-LuminexCorporation-Merck-Co-Nanobiotix-and-Novartis. html. [Accessed 26 January 2022].

116. B. A. Jnr, "Use of Telemedicine and Virtual Care for Remote Treatment in Response to COVID-19 Pandemic," Journal of Medical Systems, vol. 44, no. 132, pp. 1-9, 2020.

117. S. B. e. al, "Telemedicine Across the Globe-Position Paper From the COVID-19 Pandemic Health System Resilience PROGRAM (REPROGRAM) International Consortium (Part 1)," Frontiers in Public Health, vol. 8, pp. 1-15, 2020.

118. P. D. H.-P. H. Dekan, "Telemedicine for Improving Access to Health Care in Resource-Constrained Areas - from Individual Diagnosis to Strengthening Health Systems," Basel, 2006.

119. B. D. e. al, "Telemedicine: A systematic review of economic evaluations," Medical Journal of the Islamic Republic of Iran (MJIRI), vol. 31, no. 113, pp. 1-8, 2017.

120. A. K. e. al, "Telemedicine, the current COVID-19 pandemic and the future: a narrative review and perspectives moving forward in the USA," Family Medicine and community Health, pp. 1-9, 2020.

121. M. L. V. Marina Serper, "Current and Future Applications of Telemedicine to Optimize the Delivery of Care in Chronic Liver Disease," AGA Institute, Pennsylavinia, 2018.

122. T. E. e. al, "American College of Allergy, Asthma \& Immunology Position Paper on the Use of Telemedicine for Allergists," Elsevier, pp. 1-6, 2017.

123. R. V. T. e. al, "Telehealth," The New England Journal of Medicine, Massachusetts, 2021.

124. K. Ashford, "1 In 5 People Would Switch Doctors For Video Visits," Forbes, 30 January 2017. [Online]. Available: https://www.forbes.com/sites/kateashford $/ 2017 / 01 / 30 /$ videodoctor $/$ ?sh $=492 \mathrm{c} 8010 \mathrm{cecb}$. [Accessed 17 January 2022].

125. M. S. e. al, "Four Factors Driving the Momentum of Telehealth Adoption That Will Continue After the COVID-19 Crisis," Point of Care Partners, June 2020. [Online]. Available: https://www.pocp.com/ 
hit-perspectives-factors-driving-telehealth. [Accessed 17 January 2022].

126. T. C. O. Hashiguchi, "Bringing health care to the patient: An overview of the use of telemedicine in OECD countries," OECD, Paris, 202.

127. Baird, "4 key elements to a great telemedicine system," Becker's Healthcare, 12 January 2015. [Online]. Available:https://www.beckershospitalreview.com/ healthcare-information-technology/4-key-elementsto-a-great-telemedicine-system.html. [Accessed 17 January 2022].

128. J. FRANKENFIELD, "Cloud Computing," investopedia. com, 28 July 2020. [Online]. Available:https://www. investopedia.com/terms/c/cloud-computing.asp. [Accessed 26 January 2022].

129. L. Wainstein, "Cloud-Based Telehealth Defined: Advantages, Applications, and Security," University of Arizona, 26 June 2018. [Online]. Available:https:// telemedicine.arizona.edu/blog/cloud-based-telehealth-defined-advantages-applications-and-security. [Accessed 26 January 2022].

130. Z. R. e. al, "Impact of coronavirus pandemic crisis on technologies and cloud computing applications," Journal of Electronic Science and Technology, vol. 19, no. 1, pp. 1-12, 2021.

131. S. A. e. al, "The role of cloud computing technology: A savior to fight the lockdown in COVID 19 crisis, the benefits, characteristics and applications," International Journal of Intelligent Networks, vol. 2, p. 166-174, 2021.

132. A. R. Renato, "An Analysis of Telemedicine Experiences and Services in Chile," in Telehealth, IntecOpen, 2019.

133. B. Monegain, "Telehealth in growth mode worldwide," HealthcareITNews, 22 January 2013. [Online]. Available: https://www.healthcareitnews.com/news/ telehealth-growth-mode-worldwide. [Accessed 17 January 2022].

134. T. Monitor, "Weekly data: Telehealth investment booms after pandemic proves its worth," TECHMONITOR, 2 June 2021. [Online]. Available: https:// techmonitor.ai/leadership/digital-transformation/ weekly-data-telemedicine-investment-booms-afterpandemic-proves-its-worth. [Accessed 18 January 2022].

135. C. Stewart, "Projected growth in global healthcare data volume 2020," Statista.com, 24 September 2020. [Online]. Available: https://www.statista.com/ statistics/1037970/global-healthcare-data-volume/. [Accessed 18 January 2020].

136. B. Yolanda Smith, "Types of telemedicine," news-medical. net, 1 April 2021. [Online]. Available: https://www. news-medical.net/health/Types-of-Telemedicine. aspx. [Accessed 18 January 2022].

137. I. K. e. al, "Telemedicine - Meaning, Challenges and Opportunities," Siriraj Medical Journal, vol. 71, no. 3, pp. 1-8, 2019.

138. R. S. W. e. al, "Telemedicine, Telehealth, and Mobile Health Applications That Work: Opportunities and Barriers," American Journal of Medicine, vol. 127, no. 3, pp. 1-5, 2014.

139. D.-K. K. e. al, "A mobile telemedicine system for remote consultation in cases of acute stroke," Journal of Telemedicine and Telecare, vol. 15, no. 2, pp. 1-6, 2009.

140. V. R. Wullianallur Raghupathi, "Big Data analytics in healthcare: promise and potential," Health Information Science and Systems, pp. 1-11, 2014.

141. C. K. R. Jimeng Sun, "Big Data analytics for healthcare," in Proceedings of the 19th ACM SIGKDD international conference on Knowledge discovery and data mining, 2013.

142. A. P. Nishita Mehta, "Concurrence of Big Data analytics and healthcare: A systematic review," International Journal of Medical Informatics, pp. 1-9, 2018.

143. M. C. Blagoj Ristevski, "Big Data Analytics in Medicine and Healthcare," Journal of Integrative Bioinformatics, pp. 1-5, 2018.

144. R. P. e. al, "Benefits and challenges of Big Data in healthcare: an overview of the European initiatives," European Journal of Public Health, vol. 29, no. 3, pp. 1-5, 2019.

145. S. Dash, "Big Data in healthcare: management, analysis and future prospects," Big Data, vol. 6, no. 54, 2019. 
146. S. Durcevic, "18 Examples Of Big Data Analytics In Healthcare That Can Save People," datapine, 21 October 2020. [Online]. Available: https://www.datapine.com/blog/big-data-examples-in-healthcare/. [Accessed 26 January 2022].

147. T. C. Illinois, "Applications and Examples of Big Data in Healthcare:How Big Data Improves Efficiency, Costs, and Patient Outcomes," Touro College Illinois, 11 March 2021. [Online]. Available: https://illinois. touro.edu/news/applications-and-examples-of-bigdata-in-healthcare.php. [Accessed 26 January 2022].

148. L. B. Naoual El Aboudi, "Big Data Management for Healthcare Systems:Architecture, Requirements, and Implementation," Advances in Bioinformatics, pp. 1-11, 2018.

149. V. Gaul, "Big Data Analytics in Healthcare Market by Component (Software and Services), Deployment (On-Premise and Cloud), Analytics Type (Descriptive Analytics, Predictive Analytics, Prescriptive Analytics, and Diagnostic Analytics), Application (Clinical Analytic," Allied Market Research, December 2018. [Online]. Available: https://www.alliedmarketresearch. com/big-data-analytics-in-healthcare-market. [Accessed 26 January 2022].
150. InformIT, "Big Data Adoption and Planning Considerations," informIT, 6 February 2016. [Online]. Available: https://www.informit.com/articles/ article. $\operatorname{aspx} ? \mathrm{p}=2473128 \&$ seqNum $=11$. [Accessed 27 January 2022].

151. S. E. White, "A review of Big Data in health care: challenges and opportunities," Bioinformatics, pp. 1-6, 2014.

152. D. S. Smys, "SURVEY ON ACCURACY OF PREDICTIVE BIG DATA ANALYTICS IN HEALTHCARE," Journal of Information Technology and Digital World, vol. 01, no. 02, pp. 1-10, 2019.

153. J. Bresnick, "Top 10 Challenges of Big Data Analytics in Healthcare," Health IT Analyttics,12June2017. [Online].Available:https://healthitanalytics.com/ news/top-10-challenges-of-big-data-analytics-inhealthcare. [Accessed 18 january 2022].

154. B. Trofimov, " 5 Challenges Of Big Data Analytics in 2021," RTInsights, 2021 February 2021. [Online]. Available: https://www.rtinsights.com/5-challengesof-big-data-analytics-in-2021/. [Accessed 26 January 2022].

155. M. Research, "TOP 10 COMPANIES IN HEALTHCARE ANALYTICS MARKET," METICULOUS BLOG, 20 December 